Estudios Constitucionales, Año 8, No 1, 2010, pp. 201 - 248.

ISSN 0718-0195

Centro de Estudios Constitucionales de Chile Universidad de Talca

"Control preventivo obligatorio: Auge y caída de la toma de razón al legislador"

Sergio Verdugo R.

\title{
CONTROL PREVENTIVO OBLIGATORIO: AUGE Y CAÍDA DE LA TOMA DE RAZÓN AL LEGISLADOR ${ }^{1}$
}

\author{
COMPUlSORY EX ANTE CONTROL: \\ RAISE AND FALL OF THE CONTROL OVER THE LEGISLATOR
}

\author{
Sergio Verdugo R..$^{2-3}$ \\ Profesor-Investigador \\ Universidad del Desarrollo \\ sverdugor@udd.cl
}

RESUMEN: El autor critica la mantención de la atribución del Tribunal Constitucional relativa al control preventivo obligatorio de las leyes, contenida en el artículo 93, número 1, de la Constitución Política. Luego de aclarar su especial naturaleza jurídica, analiza y pondera las ventajas y desventajas de dicho sistema de control, utilizando para ello bibliografía nacional y extranjera. La existencia de lo que el autor llama el sello de constitucionalidad agrava las desventajas. Luego, dedica una sección a la motivación de las sentencias generadas en este tipo de control, cuestionando su utilidad. Para ello, hace un estudio teórico y empírico de la jurisprudencia del Tribunal Constitucional en los últimos años.

ABSTRACT: The author criticizes the power of the Constitutional Court to exercise compulsory ex-ante control of statutes, established in article 93, number 1, of the Chilean Constitution. After clarifying its special juridical nature, he analyzes the advantages and disadvantages of this system of control, using national and foreign bibliography. The existence of a constitutional seal aggravates the disadvantages. Then, he dedicates a section to study the motivation of the judgments generated in this type of control, questioning its value. For such purposes he makes a theoretical and empirical study of the jurisprudence of the Chilean Constitutional Court in the last years.

PALABRAS CLAVE: Tribunal Constitucional, control preventivo, control ex ante, control constitucional, control obligatorio, motivación de las sentencias, fundamentación de las sentencias.

KEY WORDS: Constitutional court, preventive control, ex-ante control, constitutional control, compulsory control, motivation of the constitutional judgments.

\footnotetext{
${ }^{1}$ Artículo recibido el 29 de diciembre de 2009 y aceptado el 19 de marzo de 2010.

${ }^{2}$ Abogado, Universidad del Desarrollo (UDD). Profesor-investigador jornada completa en la UDD.

${ }^{3}$ Agradezco la colaboración de Natalia Fajardo, ayudante de la Dirección de Investigación de la Universidad del Desarrollo. Asimismo, agradezco a los asistentes del Coloquio de Justicia Constitucional de la Universidad Diego Portales y, en especial, los comentarios de José Francisco García, Patricio Zapata, Hugo Tórtora, José Manuel Díaz de Valdés, Sebastián Zárate, Javier Couso, Rodolfo Figueroa y Nicolás Enteiche.
} 
"El control de constitucionalidad a priori, abstracto y realizado por una corte constitucional separada, es un control equivocado, en el momento equivocado y efectuado por la corte equivocada."

Martin Shapiro ${ }^{4}$

\section{INTRODUCCIÓN}

En este trabajo busco profundizar en la conveniencia o inconveniencia de mantener el control preventivo obligatorio de constitucionalidad (también llamado control preceptivo, que se opone al facultativo o eventual) del art. 93, № 1, de la Constitución Política de la República (la "CPR”) por parte del Tribunal Constitucional (el “TC”), el que tiene lugar para las leyes orgánicas constitucionales (las "LOC”), las leyes interpretativas de la CPR y los tratados internacionales cuando versan sobre materias propias de LOC. ${ }^{5}$

La tesis central de este trabajo es afirmar la inconveniencia de mantener este control. Ello se demostrará mediante el examen de las razones que lo justifican, todas las cuales son rebatibles o susceptibles de ser relativizadas, y de las razones que lo desacreditan, algunas de las cuales cobran especial fuerza. ${ }^{6}$

Hago presente que las críticas que se desarrollan en este trabajo no están dirigidas al control eventual (art. 93, No 3 de la CPR), ni al control represivo (art. 93, $\mathrm{No}^{\circ}$. 6 y 7 de la CPR). La naturaleza del control eventual es muy diferente a la del control obligatorio, razón por la cual no me haré cargo de esto último en este trabajo. Las diferencias radican en aspectos procesales fundamentales, ${ }^{7}$ y en la utilidad del mismo control. ${ }^{8}$

Este trabajo se divide en dos secciones:

En la sección I, titulada "naturaleza y discusión acerca de la conveniencia del control preventivo obligatorio", revisaré la doctrina existente al respecto, repasando

\footnotetext{
${ }^{4}$ SHAPIRO (1993) p. 479.

${ }^{5}$ Esta última se introdujo por la reforma constitucional de la Ley 20.050, del 2005. Esta materia ya había sido discutida con anterioridad en sentencia del Tribunal Constitucional. Convenio № 169 sobre pueblos indígenas, adoptado por la Organización Internacional del Trabajo, de 27 de junio de 1989. Rol No 309-2000.

${ }^{6}$ Hago presente que, no obstante mis dudas en la mantención del control preventivo obligatorio, lo anterior no altera en absoluto mi posición acerca de la conveniencia de contar con un sistema de leyes de quórum super mayoritario como las LOC. Sobre este aspecto, puede verse mi posición en Verdugo (2009a).

${ }^{7}$ En el control eventual hay requerimiento, partes, conflicto visible, duda de constitucionalidad, y en el control obligatorio no.

${ }^{8}$ El control eventual permite que las minorías parlamentarias ejerzan un control respecto de las mayorías en aspectos tan relevantes como el respeto por quórum de las leyes de super mayoría y las ideas matrices del proyecto de ley en tramitación. El control eventual es, además de una herramienta revisora del contenido del proyecto de ley, un eficaz instrumento de control de las etapas de la formación de dicha ley y de su ritualidad procedimental. Lo anterior no sucede respecto del control obligatorio. Podría pensarse que este último es útil para controlar el cumplimiento del quórum, pero ello no es efectivo, como argumentaré más adelante.
} 
el debate y tomando partido en cada uno de los puntos que se plantean. Revisaré a los autores que han tomado posición. Entre ellos, encontramos detractores como Shapiro y Bordalí, ${ }^{9}$ y también partidarios, como Moderne, Bon y Alegre. ${ }^{10}$ La estructura de esta sección exige comenzar haciendo algunos comentarios relativos a la naturaleza política o jurídica (o jurisdiccional) de este tipo de control, ya que es allí donde comienzan las críticas y, también, las diferencias del control obligatorio que lo distinguen de otros controles. En seguida, repasaré de manera crítica las ventajas que se han invocado para defender el control obligatorio. Luego, trataré acerca de las desventajas, que se fortalecen si se consideran los efectos de la sentencia constitucional.

En la sección II, titulada "Dogmática constitucional en las sentencias del Tribunal Constitucional emanadas del control preventivo y obligatorio de constitucionalidad", inten taré constatar la práctica reciente del TC en esta materia, tomando una muestra de sentencias que determinaré. ${ }^{11}$ En esta sección, intentaré observar de qué manera el TC colabora al sistema jurídico con este tipo de control.

\section{SECCIÓN I \\ NATURALEZA Y DiSCUSIÓN ACERCA DE LA CONVENIENCIA DEL CONTROL PREVENTIVO OBLIGATORIO}

Llama la atención la escasez de literatura nacional en esta materia, sobre todo si se considera que el control preventivo es una excepción en el derecho comparado. ${ }^{12}$ La historia de la norma chilena tampoco aporta mucho. ${ }^{13}$ De hecho, el

\footnotetext{
${ }^{9}$ Shapiro (1993); Bordalí (2005) p. 256. Aunque breve, hay que destacar las dudas que manifestó el profesor Ortúzar en la Comisión de Estudios de la Nueva Constitución. Véase la sesión 344, de 4 de abril de 1978.

${ }^{10}$ Moderne (1993); Bon (1993); Alegre (2007).

${ }^{11}$ Véase al final de este trabajo el anexo que incluye el resumen de este estudio jurisprudencial.

${ }^{12}$ Favoreu (1994) p. 36; Moderne (1993) p. 411; Bon (1993) p. 389. Además de Francia y Chile, otros países que tienen este sistema son Portugal y Colombia. Sobre el sistema constitucional de Portugal véase, entre otros, a Gomes (2000); Favoreu (1994) pp. 126-131. Sobre el sistema de control constitucional de Colombia véase, entre otros, a Cifuentes (2002). Otro país que tuvo un sistema de control preventivo obligatorio, pero lo eliminó, es España. Sobre el debate en España véase, entre otros, a Alegre (2007). Cabe hacer presente que, si bien EE.UU. nunca ha tenido un control preventivo obligatorio de la constitucionalidad de las leyes, en los inicios del constitucionalismo americano se consideró la posibilidad de instaurar un "Consejo de Revisión", iniciativa que finalmente no prosperó. Véase Kramer (2001) pp. 64-65; GARCíA (2003) pp. 505-506; SHAPIRO (1993) p. 475. Este último autor anota que, no obstante lo anterior, existe una especie de control a priori en la facultad de veto del Presidente de la República. SHAPIRo (1993) pp. 476-477. Este "control", también existente en Chile, tiene características muy distintas respecto del que analizo en este trabajo, razón por la cual no profundizo en el mismo.

${ }^{13}$ La idea de establecerlas en Chile fue promovida por Raúl Bertelsen en la Comisión de Estudios de la Nueva Constitución. Son pocos los antecedentes que existen relativos al establecimiento del control obligatorio,
} 
sistema chileno importó parcialmente el francés, y este último no buscó imitar ningún modelo preestablecido. ${ }^{14}$ Creo que la carga de probar la conveniencia de un sistema de control es de quienes lo defienden y, sin embargo, poco se ha dicho. Tal vez el único trabajo nacional que se hace cargo de gran parte de los argumentos involucrados específicamente en esta materia es el de Bordalí, quien se manifiesta crítico. ${ }^{15}$

Sin perjuicio de lo anterior, existen trabajos extranjeros que son útiles. Algunos tratan la materia de manera específica (o a lo menos referidos al sistema francés) ${ }^{16}$ y otros describen el tema que estudio con un enfoque comparado de los sistemas de Justicia Constitucional. ${ }^{17}$

En la doctrina nacional existen varios trabajos que son útiles, pese a que no se refieren específicamente a la conveniencia o inconveniencia de que exista el control preventivo obligatorio. Un grupo de estos trabajos describe los problemas prácticos que se han suscitado en el ejercicio de este tipo de control. ${ }^{18}$

Otro grupo de trabajos se refieren específicamente a las LOC, tratando nuestro tema de manera indirecta. La mayoría de ellos busca describir las características, el origen, fundamento y la naturaleza de las LOC, ${ }^{19}$ y otros se refieren a la crítica democrática de la regla super mayoritaria que tienen las mismas para su aprobación parlamentaria. De esta última materia también se ha escrito bastante poco

ya que la mayoría dicen relación con el quórum de las LOC. En especial, las sesiones más importantes que tratan la materia, aunque brevemente, son las siguientes: sesión 344, de 4 de abril de 1978; 353, de 19 de abril de 1978; 358, de 25 de abril de 1978. Por otra parte, en las actas del Consejo de Estado, hay breves intervenciones en la materia. Véanse por ejemplo las sesiones 86, de 21 de agosto de 1979; 87, de 28 de agosto de 1979; y 110, de 1 de julio de 1980. Véanse estas actas en ArANCiBIA et al (2008).

${ }^{14}$ BON (1993) p. 382.

${ }^{15}$ Bordalí (2005). Esta idea crítica también ha sido planteada, aunque brevemente, en VARGAS et al (2001) p. 158 y p. 190.

${ }^{16}$ Entre ellos, véase a Friedrich (1959); Beardsley (1972); Tallon (1979); Gomes (2000); Cifuentes (2002); Alegre (2007); Shapiro (1993). Algunos ensayos de doctrina francesa que se han divulgado entre nosotros por la Revista Chilena de Derecho son: Bon (1993); Renoux (1993); Moderne (1993); MeysonRenoux (1993). La utilidad de estos últimos trabajos es obvia: fueron los franceses los que inventaron el control preventivo obligatorio en la CPR de 1958. "Es el caso francés, sin lugar a dudas, el sistema en el que el control previo adquiere mayor importancia”. MODERNE (1993) p. 411.

${ }^{17}$ Entre ellos, Rosseau (2002); FAVOREu (1994); MorTON (1988). Entre nosotros, puede verse un estudio de la Justicia Constitucional francesa en ZapatA (2008) pp. 79-87 y 448-454 y DE LA CruZ (2007) pp. 51-57.

${ }^{18}$ Entre ellos, Pfeffer (1998); Aldunate (2005); Buchheister et al (2005); Zapata (2008) pp. 432-448; Henríquez (2009) pp. 63-70.

19 Ríos 1983; Bulnes 1984; Caldera 1984; Ministerio Secretaría General de la Presidencia 2000, pp. 202-216 y pp. 398-401; Zapata 2008, pp. 395-458; Verdugo 2009b; Henríquez 2009, pp. 63-71. 
en la doctrina nacional, ${ }^{20}$ aunque es posible encontrar breves (y no por eso menos valiosos) párrafos en ciertos libros. ${ }^{21}$

En esta sección trataré la discusión existente en cuanto a la naturaleza jurídica del control preventivo obligatorio y, desde allí, se estudiarán las ventajas y desventajas del mismo.

\section{NATURALEZA POLÍTICA O JURISDICCIONAL (O JURÍDICA) DEL CONTROL PREVENTIVO OBLIGATORIO}

Un primer problema a despejar es la naturaleza del control preventivo. Como ya lo decía en la introducción, este problema es muy importante, ya que a partir de él se construyen las ventajas y desventajas. Asimismo, a partir de estas distinciones podemos separar las características propias de este tipo de control respecto de otras actividades de la justicia ordinaria y, también de la constitucional.

Por una parte, hay quienes profesan una crítica escéptica, según la cual el control preventivo es un control político, por lo que sería inconveniente adoptar el mismo. ${ }^{22}$ Por otro lado, existen algunos que sostienen que se trata de un control de tipo jurídico o jurisdiccional.

Sin perjuicio de la importancia de estas visiones antagónicas, hay que hacer presente que ambas sufren de una debilidad que hay que superar: si se piensa que el control constitucional siempre es político, ${ }^{23}$ no importando su carácter preventivo o represivo, difuso o concentrado, entonces jamás llegaremos a plantear el punto. Desde luego, y sin perjuicio de que esta debilidad existe en el mundo académico, me haré cargo del debate asumiendo que superamos la misma. ${ }^{24}$

\footnotetext{
${ }^{20}$ MuÑOZ (2006); VeRdugo (2009).

${ }^{21}$ Zapata (2008) pp. 402-404; Henríquez (2009) p. 71.

${ }^{22}$ Entre otros autores, es partidario de esta crítica MesQuita (2007) pp. 291 y 297-299; Burdeau, citado por Bon (1993) p. 386. Sobre este punto, véase a Bordalí (2005) pp. 223-227.

${ }^{23}$ Sobre este aspecto, destaco el trabajo de MORTON (1988), ya que aplica esta discusión democrática general en un contexto de comparación de sistemas: el francés y el de EE.UU. Este autor incluso llega a sugerir que el Consejo Constitucional francés es más político que la Corte Suprema americana. MoRTON (1988) p. 99. Este autor llega incluso a cuestionar que el Consejo francés sea una verdadera Corte. MorTON (1988) p. 106. Este mismo cuestionamiento se ha esbozado brevemente en el rol del Tribunal Constitucional chileno cuando ejerce el control preventivo. Véase Ríos (1983) p. 42. Sin que se hayan dado mayores detalles, hay que precisar que estas dudas fueron planteadas de manera muy general por Lorca en la Comisión de Estudios de la Nueva Constitución. Véase la sesión 358, de 25 de abril de 1978.

${ }^{24}$ Quien comenzó cuestionando que el control constitucional sea, efectivamente, jurisdicción, fue Carl Schmitt, en sus ensayos "El Tribunal de Estado como Guardián de la Constitución" y "El Guardián de la Constitución". La respuesta de Hans Kelsen no esperó, y publicó en 1931 su famoso ensayo titulado "¿Quién debe ser el guardián de la Constitución?” para demostrar que el control constitucional es un control de tipo jurídico, hecho por un tercero independiente. En este texto Kelsen reafirma y defiende la creación de los tribunales
} 
La crítica escéptica se fundamenta en que el órgano contralor actúa antes de que la ley entre en vigencia, formando parte del procedimiento legislativo, y en que el efecto de dicho control no implica reparar una infracción al ordenamiento jurídico, sino evitar la producción de la misma, ${ }^{25}$ en que los integrantes del órgano contralor no son jueces, ${ }^{26} \mathrm{y}$ en que no existe un procedimiento adversarial..$^{27}$ En el evento de aceptar esta crítica escéptica, nace el cuestionamiento relativo a que el órgano llamado a ejecutarlo (sea un TC o un Consejo Constitucional) se convertiría en una tercera cámara legislativa, ${ }^{28}$ pero sin la misma legitimidad democrática de una cámara electa popularmente. ${ }^{29}$ Esta parece ser la razón que llevó a los españoles a abandonar el sistema de control preventivo, y mantenerlo sólo para los tratados internacionales. ${ }^{30}$

Esta crítica parece responder a la realidad de la primera manifestación histórica del control preventivo, ${ }^{31}$ ya que su fin era esencialmente político. En efecto, dicho control estaba en manos de la primera versión del Consejo Constitucional francés,

constitucionales. Véase KeLSEN (2002). Este importante autor, arquitecto de los tribunales constitucionales, ve en el TC a un órgano de naturaleza política-jurisdiccional. Política porque resuelve problemas políticos y jurisdiccional porque resuelve la controversia aplicando el Derecho. Kelsen (2002) pp. 19-21.

${ }^{25}$ Moderne (1993) p. 410.

${ }^{26}$ Haciendo aplicable esta crítica al Consejo Constitucional francés, véase TALlon (1979) pp. 568-569; MesQuiTa (2007) p. 297. Como expresión de ello, la autora fundamenta la actitud de moderación de dicho Consejo, y la existencia de actos de gobierno que no están sujetos a control alguno. Por otra parte, se ha dicho que los miembros del Consejo francés normalmente tienen la misma afinidad política que los legisladores. BEARDSLey (1972) p. 439; MorTon (1988) p. 91.

${ }^{27}$ Friedrich (1959) p. 826. Aldunate agrega que el control obligatorio hace imposible la imparcialidad (elemento sustancial al concepto mismo de jurisdicción), por cuanto es el propio órgano controlador el que busca el vicio constitucional en el precepto controlado, luego lo estudia y lo resuelve. AldunATE (2005) p. 123.

${ }^{28}$ Se trataría de un órgano que realiza su función con criterios políticos, y no necesariamente de Derecho. Véase Mesquita (2007) p. 298; Bon (1993) p. 386; Bordalí (2005) p. 217. Incluso, se ha dicho que el Consejo puede dar indicaciones. De la Cruz (2007) p. 55. Independiente de que esta crítica sea cierta o no, no puede desconocerse que el Consejo actúa dentro del proceso legislativo. RousSEAU (2002) p. 24. La idea de la tercera cámara ha sido expresamente rechazada por FAVOREU (1994) p. 112.

${ }^{29}$ Ello nos reenvía a la ya conocida discusión acerca de la legitimidad de la Justicia Constitucional. Además del trabajo de Morton (ya citado), entre muchísimos autores véase el debate nacional entre ATRIA (1993) (2000) y ZAPATA (2008) pp. 15-72.

${ }^{30}$ Alegre (2007); Bordalí (2005) p. 217; Moderne (1993) pp. 414-415. Esta crítica se agudizó en España debido a la duración excesiva del control, lo que entorpecía la actividad legislativa, con todos los costos políticos que ello significa. Véase Moderne (1993) p. 416; Bon (1993) p. 393.

${ }^{31}$ Bordalí (2005) p. 215. Otro autor va mucho más allá, al sostener que la Carta francesa de 1958 fue "escrita por la derecha para la derecha”. MORTON (1988) p. 105 (traducción propia). De esta manera, se sugiere un vínculo ineludible con la naturaleza política del Consejo Constitucional francés. 
un órgano que en su origen estaba destinado a racionalizar el poder del legislador ${ }^{32}$ y a fortalecer al Poder Ejecutivo, ${ }^{33}$ lo que era coherente con la política degaullista que inspiró la Carta francesa de 1958..$^{34-35}$ Asimismo, el control político del Consejo se justificaba en la medida en que las normas constitucionales que estaban destinadas a defender eran sólo orgánicas o relativas al procedimiento legislativo, y no decían relación con el preámbulo de la Constitución de 1958. ${ }^{36}$

Sin embargo, en Francia esta visión ha sido abandonada y hoy la mayoría sostiene que el control preventivo obligatorio es de tipo jurisdiccional o jurídico ${ }^{37}$ debido a las siguientes razones: que el órgano llamado a ejercer el control no fija al legislador los términos de la ley ni interviene en su contenido; ${ }^{38}$ emplea métodos jurídicos en el mismo; ${ }^{39}$ y tiene la obligación de fallar en Derecho. ${ }^{40}$ De esta manera, el control obligatorio sólo vigila que "disposiciones constitucionales puedan

\footnotetext{
${ }^{32}$ Así, la función del Consejo Constitucional es asegurar que las restricciones al Parlamento se mantuvieran. FRIEDRICH (1959) p. 824.

33 Beardsley (1972) pp. 436-438; Tallon (1979) p. 570; Morton (1988) p. 90; Zapata (2008) p. 80; De LA Cruz (2007) p. 53; Bon (1993) p. 382. El Consejo Constitucional era un "guardián del parlamento". Se buscaba obligarlo a mantenerse en el marco de su competencia. Bon (1993) p. 383. Así, el Consejo era sólo un defensor de la Potestad Reglamentaria. Sobre el presidencialismo francés, véase FrIEDRICH (1959) pp. 814-822. Este mismo autor trata las limitaciones de la función parlamentaria de la Carta de 1958. FRIEDRICH (1959) pp. 822-826.
}

${ }^{34}$ ZAPATA (2008) p. 81.

${ }^{35}$ Sin perjuicio de que no conozco trabajos académicos que hagan esta crítica a Chile, parece ser un lugar común en estos días encontrar en la prensa quienes ven en el control preventivo obligatorio una manera del Gobierno Militar (1973-1990) de revisar las modificaciones a la "legislación de amarre" que la Junta de Gobierno habría dejado con las LOC. Parece ser que esta crítica se dirige más bien a las LOC y a la regla de super mayoría. Sin embargo, si se acepta que esta crítica es cierta, no se salva el hecho de que el control pueda volverse jurídico debido a la actuación del órgano de control respectivo, tal y como ocurrió en Francia. Por eso, esta crítica es más que nada contextual, y no responde a un juicio abstracto y teórico acerca del control en sí, ya que aceptaría la existencia del mismo en el evento que se den ciertas condiciones de contexto. Sobre la discusión democrática de las LOC, véase entre otros a (MuÑoz 2006; VERDUGO 2009; ZAPATA 2008 pp. 402-404; HenríQuez 2009 p. 71).

${ }^{36}$ Bon (1993) p. 384. Sobre las razones jurídicas que llevaron al Consejo Constitucional a utilizar el preámbulo como norma justiciable, véase Beardsley (1972) pp. 442-448; Favoreu (1994) pp. 107-108. Véase también TAlLON (1979) p. 571; y MORTON (1988) p. 90.

${ }^{37}$ Bordalí (2005) p. 227. Esto es lo que opina la mayoría de los autores franceses. Moderne (1993) p. 411. En España, véase la opinión de Alegre (2007).

${ }^{38}$ Moderne (1993) p. 410.

${ }^{39}$ Renoux (1993) p. 444.

${ }^{40}$ No cabría señalar que este control tiene una naturaleza meramente política, ya que -pese a no ser estrictamente jurisdiccional- es un control de derecho, ya que no está excluido del mandato del art. 92 de la CPR (“... el Tribunal fallará de acuerdo a derecho”). Véase además Ministerio Secretaría General de la PRESIDENCIA (2000) p. 399. 
alterarse por la vía de esas leyes orgánicas que están destinadas a aplicarlas”. ${ }^{41}$ Esto es coherente con la jurisprudencia del Consejo Constitucional, que comenzó a utilizar el preámbulo de la Constitución de 1958 como norma constitucional vinculante, dándole especial preeminencia a las libertades. ${ }^{42}$ Esta idea no estaba en la mente del constituyente original. ${ }^{43}$ Sin perjuicio de ello, existe una duda consistente en si el Consejo, al proteger derechos fundamentales, está o no invadiendo las prerrogativas del juez ordinario. ${ }^{44.45}$

Como una crítica a esta visión, debe decirse que lo jurídico está confundido con lo jurisdiccional. En mi opinión, lo jurisdiccional dice relación con la existencia de un tercero imparcial llamado a resolver un conflicto de relevancia jurídica, lo que no existe en la especie; mientras que lo jurídico dice relación con el fin del acto que dictará el órgano de control. Si el fin de dicho acto es aplicar el Derecho, entonces el mismo es jurídico, y si su fin es aplicar un criterio político, entonces el mismo será -valga la redundancia- de naturaleza política. De esta manera, está claro que el control obligatorio no es jurisdiccional, pero sí jurídico. La función del juez constitucional es diferente a la del juez ordinario. En este sentido "el juez judicial (...) falla en los casos particulares de aplicación de la ley, y el otro (el juez constitucional) en relación con la validez general de la norma con respecto a la Constitución." ${ }^{46}$

No es, entonces, un control político, aunque sí puede convertirse en un control politizado. La diferencia radica en que en el control politizado el fin político no es perseguido por las normas que disponen la existencia del control, y la politización se produce como una consecuencia no deseada. En cambio, el control politico tiene fines directamente (valga nuevamente la redundancia) políticos, como ocurrió con la primera versión del Consejo Constitucional francés, según ya expliqué.

Pese a todo, la suspicacia que levanta la crítica escéptica no es menor, sobre todo si se consideran las características procesales del mismo control, las que

\footnotetext{
${ }^{41}$ Bon (1993) p. 383.

${ }^{42}$ El comienzo de este cambio jurisprudencial se debió al famoso caso titulado "libertad de asociación". Sobre un completo desarrollo y comentario de este caso, véase BEARDSLey (1972) pp. 432-436. Hoy, gracias a la jurisprudencia sentada en ese caso, el Consejo Constitucional es un "eficaz guardián" de dichas libertades. ZAPATA (2008) p. 81.

${ }^{43}$ Beardsley (1972) p. 440; Bon (1993) p. 384 y 388. Para este último autor, además de lo ya dicho, hoy el Consejo se ha transformado en un protector de las competencias del Parlamento y de los derechos de las minorías.

${ }^{44}$ Renoux (1993) p. 447; Morton (1988) p. 92.

${ }^{45}$ Por otra parte, la idea de la racionalización del Parlamento ya ha sido abandonada. ZAPATA (2008) p. 450.

${ }^{46}$ Renoux (1993) p. 445.
} 
son del todo ajenas a un sistema procesal jurisdiccional que otorgue garantías propias del debido proceso, ${ }^{47}$ como ocurre con la ausencia del principio de contradictoriedad y la motivación de las sentencias, ${ }^{48}$ además de la publicidad de sus actuaciones. A ello se suma el hecho de que las materias propias de las LOC "dicen relación con temas trascendentes, como son los políticos". ${ }^{49}$ Por otra parte, no puede desconocerse que, en los hechos, este tipo de control puede verse rodeado de circunstancias políticas que hace que se "preste a ser utilizado para

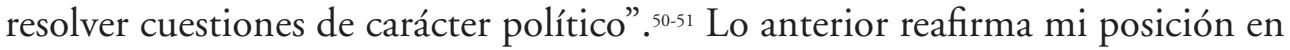
el sentido de que este control puede politizarse, pero no por eso deja de ser un control jurídico.

Teniendo claro que la naturaleza del control es jurídica (y no jurisdiccional), será más fácil examinar las ventajas y desventajas que se han invocado para defender o criticar la existencia del control preventivo obligatorio. Veamos en primer lugar las ventajas.

\section{VENTAJAS DEL CONTROL PREVENTIVO OBLIGATORIO}

Las ventajas que se han invocado para defender el control preventivo obligatorio son las siguientes: 1. Este control tiende a evitar los "efectos traumáticos de la anulación de una norma inconstitucional; 2. Evita la generación de la responsabilidad internacional; 3. Implica una "extrema" rapidez y sencillez en el mismo control; 4. Fortalece el principio de igualdad ante la ley; 5 . Utilidad para el respeto parlamentario del quórum de las LOC..$^{2}$

\footnotetext{
47 "En el control preventivo no hay derecho al debido proceso que respetar". Bordalí (2005) p. 235.

${ }^{48}$ Bon (1993) pp. 391-392.

${ }^{49}$ Caldera (1984) p. 456. También hay un autor que sostiene que las LOC son de "índole predominantemente política”. Ríos (1983) p. 39. Si conectamos la naturaleza del control obligatorio con las materias que son objeto de la norma a controlar (las LOC) entonces con esta lógica el control mismo sería político.

${ }^{50}$ Moderne (1993) p. 410. Por otro parte, el Consejo Constitucional "resuelve cuando los clamores del debate parlamentario todavía no se han apagado, el juez constitucional interviene en el terreno todavía candente de las pasiones políticas". MORTON (1988) p. 95; Bon (1993) p. 390. Un buen ejemplo en Chile lo constituye la sentencia del Tribunal Constitucional. Ley No 18.460, Orgánica Constitucional sobre el Tribunal Calificador de Elecciones. Rol No 33-1985.

${ }^{51}$ Esta misma circunstancia hace reconocer a uno de los partidarios del sistema, de la necesidad de otorgar legitimidad democrática al Consejo Constitucional mediante la composición de sus miembros. Bon (1993) p. 389.

${ }^{52}$ También se ha sostenido que este tipo de control es indispensable para el respeto a la supremacía constitucional. Bulnes (1984) p. 239. Ésta parece ser la razón que inspiró a Bertelsen a proponer el control obligatorio en la Comisión de Estudios de la Nueva Constitución. Véase la sesión 353, de 19 de abril de 1978. Esta es una ventaja que será respondida cuando trate la ineficacia del control obligatorio.
} 
1. Este control tiende a evitar los "efectos traumáticos de la anulación de una norma inconstitucional", ${ }^{3}$ y no plantea, por lo tanto, los "delicados problemas que acompañan a las declaraciones de inconstitucionalidad de leyes ya aplicadas". ${ }^{54}$ Esta razón cobra fuerza si se considera que existen situaciones problemáticas derivadas del cambio normativo que implica el control, muchas de las cuales no se pueden reparar. Por todo ello, la alternativa del control obligatorio fortalece la certeza jurídica. ${ }^{55}$ En nuestro país, este problema se puede generar con el control abstracto del art. 93, No 7 de la CPR, y difícilmente se da con la declaración de inaplicabilidad (art. 93, No 6 de la CPR), debido a los efectos particulares de la misma..$^{56}$

Más que una virtud del sistema de control preventivo obligatorio, esta ventaja representa un defecto del sistema de control represivo. De aceptar que este argumento sea correcto, debe aceptarse que el control preventivo reemplaza al control represivo, con todas sus virtudes. En mi opinión, ello no es así, ya que ambos tienen diferencias sustanciales, comenzando con el tipo de control: el preventivo es necesariamente abstracto, ${ }^{57} \mathrm{y}$ el represivo es generalmente concreto, de aplicación $\mathrm{o}$, al menos, derivado de un requerimiento. ${ }^{58} \mathrm{Si}$ se trata de controles distintos, que observan vicios diferentes (abstractos por un lado y concretos por el otro) entonces no es posible reemplazar uno por el otro. Así, el argumento de los defectos del modelo de control represivo no se subsana con la incorporación del modelo preventivo.

Por lo demás, en nuestro sistema coexisten ambos tipos de control constitucional, por lo que la existencia de un control preventivo no evitará que los efectos traumáticos se produzcan. Ello se debe a que, como veremos, los preceptos legales controlados preventivamente normalmente serán declarados constitucionales y

\footnotetext{
${ }^{53}$ Moderne (1993) p. 416; Rousseau (2002) p. 56 y p. 73. En este mismo sentido se manifiesta Alegre (2007) pp. 20 у 22.

${ }^{54}$ Bon (1993) p. 390.

${ }^{55}$ Rousseau (2002) p. 54. Por otra parte, hay que hacer presente que la seguridad jurídica fue invocada por Bertelsen en la Comisión de Estudios de la Nueva Constitución. Véase la sesión 344, de 4 de abril de 1978 .

${ }^{56}$ Un buen ejemplo de esto tuvo lugar a raíz de la sentencia del Tribunal Constitucional. Inconstitucionalidad del art. 116 del Código Tributario. Rol 681-2006 (2007). Sobre este problema puede verse mi trabajo en VERDUGO (2008).

${ }^{57}$ BeARdsLey (1972) p. 439

${ }^{58}$ Ello se entiende sin perjuicio de la facultad de declarar de oficio la inconstitucionalidad de un precepto legal contrario a la CPR, lo que opera sólo si el TC ha declarado la inaplicabilidad, la que sirve de antecedente necesario a su declaración. En otras palabras, de aceptar un control represivo abstracto, este siempre tendrá una experiencia anterior que ilustrará a los jueces de los problemas que produce la norma.
} 
se insertarán al sistema jurídico, no obstante su inconstitucionalidad. Ello abre la posibilidad de que se active el control represivo y los efectos traumáticos se generen. Así, mientras no se elimine el control represivo, no se impedirán dichas consecuencias traumáticas.

Para quienes creen que el control constitucional represivo es conveniente, entre quienes me cuento, la alternativa de eliminar el mismo no es una buena idea.

2. Evita la generación de la responsabilidad internacional por causa de infringir tratados internacionales mediante el control represivo de constitucionalidad. 59-60 Parte de la doctrina ha ido más allá, proponiendo que todos los tratados internacionales sean objetos del control preventivo obligatorio, ${ }^{61}$ y otro autor cree que el sistema actual "equilibra adecuadamente el respeto al principio de supremacía constitucional (...) asegurado por el control preventivo (...) y la intangibilidad de los tratados ya ratificados". ${ }^{62}$

El fin de esta ventaja es impedir absolutamente la posibilidad de que exista control represivo respecto de los tratados declarados constitucionales. ${ }^{63}$ Se hace presente que resultaría contradictorio sostener al mismo tiempo que los tratados internacionales tienen una jerarquía constitucional, y que ellos deben ser objeto de

\footnotetext{
${ }^{99}$ Así, se eluden "los efectos negativos que podría acarrear el control represivo de constitucionalidad para la estabilidad de los compromisos internacionales y la seriedad del Estado en el ámbito internacional". Henríquez (2007) p. 120. Véase también la opinión de Bordalí (2005) pp. 228-229. Este último autor no es partidario del control obligatorio en términos generales, pero cree que es conveniente en cuanto a los tratados internacionales. Bordalí (2005) p. 256. Por otro lado, debe recordarse que en España, no obstante la derogación del control preventivo, subsiste un mecanismo previo para los tratados internacionales. Se trata de un mecanismo eventual (y no obligatorio) que funciona a requerimiento. Véase el art. 95 de la Constitución española y el art. 78 de la ley orgánica del Tribunal Constitucional. Véase además a Alegre (2007) pp. 7-8. Debe advertirse, sin embargo, que se trata de un control de tipo eventual.

${ }^{60}$ En Francia, véanse las opiniones de Moderne (1993) p. 416; Bon (1993) p. 385, quienes sostienen esta posición. Por otro lado, esto es criticado por Mesquita, quien sostiene que "en Francia, los tratados internacionales pueden ser considerados actos no justiciables, ya que el responsable por el control de constitucionalidad no es un tribunal independiente, órgano del Poder Judicial, sino una institución de naturaleza política, a saber el Consejo Constitucional.” MesQuiTa (2007) p. 291 Véanse también las pp. 296-299. Por supuesto, esta crítica sólo es procedente si sostenemos la visión escéptica acerca de la naturaleza del control preventivo y del órgano controlador.

${ }^{61}$ Henríquez (2007) p. 125; Henríquez (2009) p. 43 y pp. 48-50; Fernández (2003) p. 498; Nogueira (2007) p. 86. Esta idea incluso estuvo presente en la historia de la modificación de la CPR, del 2005. Al respecto, véase en especial la opinión de Eduardo Vio en PFefFer (2005) p. 272.

${ }^{62}$ Nogueira (2007) p. 70. No obstante, este autor constata un déficit, razón por la cual igual está dentro del grupo de doctrina que propone "el establecimiento de un control preventivo obligatorio de todos los tratados internacionales", al que agrega una alternativa: "una acción popular de inconstitucionalidad preventiva de control de constitucionalidad de tratados". NogueIra (2007) p. 86.

${ }^{63}$ Sobre la inconveniencia de la existencia de un sistema de control represivo de constitucionalidad de los tratados internacionales puede verse, entre otros, a Henríquez (2009) pp. 50-55.
} 
control constitucional, sea éste preventivo o represivo. Lo anterior se debe a que el solo hecho de proponer la existencia de un control sobre los tratados, implica lógicamente asumir que ellos son inferiores a la CPR. ${ }^{64}$

Para que esta ventaja del control preventivo sea efectivamente aplicable, deben existir las siguientes circunstancias: en primer lugar, debe haber un sistema legislativo de aprobación dentro de la gestación de los tratados internacionales. En segundo lugar, no debe existir un tipo de control represivo susceptible de generar responsabilidad internacional. Si existiendo control preventivo, igual hay control represivo, entonces esta ventaja pierde importancia de manera sustancial. ${ }^{65}$ Esta circunstancia exige que siempre exista una suerte de sello de constitucionalidad, ${ }^{66}$ respecto de los tratados internacionales.

En el caso chileno, la reciente jurisprudencia del TC admite la procedencia del recurso de inaplicabilidad, generando con ello la posibilidad de dar lugar a la responsabilidad internacional, sin perjuicio de que limite la procedencia de la declaración de inconstitucionalidad del precepto legal con efectos absolutos. ${ }^{67}$ Luego, esta ventaja no es aplicable al contexto actual chileno. Si se piensa que la inaplicabilidad es un control diferente al preventivo abstracto, entonces este último nunca impedirá la procedencia de la misma.

Lo anterior es un argumento que depende del contexto jurisprudencial actual, que por consiguiente se destruye fácilmente si se admite la posibilidad de que en el futuro la jurisprudencia del TC cambie. Por lo tanto, un cambio en la composición del mismo podría significar que sobreviva la propuesta de establecer control obligatorio para los tratados internacionales. En mi opinión, de admitirse esa posibilidad, igual no es conveniente aceptar la propuesta, por cuatro razones fundamentales:

En primer lugar, de aceptarlo, los tratados internacionales quedarían cubiertos con un sello de constitucionalidad que impediría la procedencia del control poste-

${ }^{64}$ En este sentido, una opinión similar es sostenida por Teodoro Ribera. Sin embargo, este autor acepta la importancia de que exista un control preventivo que coexista con el control represivo. Por supuesto, yo discrepo de esta opinión. Véase Ribera (2007) p. 100.

65 "Lo que se busca con el control previo de constitucionalidad es ciertamente que no haya necesidad de llegar a ejercer el control represivo". HenRíquez (2007) p. 120.

${ }^{66}$ Esta expresión está tomada de la denominada patente de constitucionalidad. Así llamab Favoreu al efecto de sustraer de la justicia constitucional un precepto legal declarado constitucional en el control preventivo. Véase FaVoreu (1994) p. 109.

${ }^{67}$ Tribunal Constitucional. Ley No 17.997, Orgánica Constitucional del Tribunal Constitucional. Rol No 1288-2008, (2009). Es importante precisar que, atendidas las mayorías relativas que se han formado al interior del TC, podría decirse que esta doctrina podría estar sujeta a cambios dependientes de la integración del TC. Triunfó parcialmente la tesis sostenida por RiBERA (2007), el que incluso fue citado por el TC. 
rior. Ello produce que las reformas constitucionales sucesivas no tengan ningún valor en el Derecho Internacional vinculante ya ratificado por el Estado. En otras palabras, si quisiéramos modificar nuestra CPR estableciendo normas opuestas o complementarias a las establecidas en algún instrumento internacional aprobado en el control preventivo obligatorio, estas modificaciones constitucionales no podrían ser aplicadas en toda su plenitud. Ello implica disminuir la potestad constituyente derivada y, en consecuencia, reducir el ámbito de la soberanía.

En segundo lugar, normalmente el TC en el control preventivo no tiene en consideración derechos fundamentales, como se verá. Lo anterior produce que el sello de constitucionalidad deje a las personas en la indefensión frente a eventuales tratados internacionales que afecten sus derechos, por cuanto nunca tuvieron la posibilidad de reclamar en contra de la legislación internacional.

En tercer lugar, si aceptamos la última desventaja que desarrollaré en este trabajo, llegaremos a la conclusión de que el control preventivo es ineficaz como control constitucional, y no da garantías de constitucionalidad, por lo que se correría el riesgo de que existan normas inconstitucionales que no pueden ser objeto de reparación. Con ello, el principio de supremacía constitucional está en juego.

En cuarto lugar, y como ya lo expliqué, el control preventivo no reemplaza al control represivo, por lo que sustituir uno por el otro es una receta inconveniente.

Los colegisladores deben ser responsables en la decisión de adoptar acuerdos internacionales. Eliminar el control represivo significa anular la posibilidad de que esa responsabilidad se genere, siendo irreprochable la conducta ilícita de quienes decidan acordar tratados internacionales contrarios a la CPR. "Más vale asumir las consecuencias de un acto inconstitucional, que permanecer en una contravención permanente al texto constitucional". ${ }^{68}$ Proponer el control obligatorio en reemplazo del control represivo equivale a dejar a los tratados sin un control constitucional efectivo, lo que es inaceptable ante el principio de supremacía constitucional. ${ }^{69}$

3. Implica una "extrema" rapidez y sencillez en el mismo control. ${ }^{\circ 0} \mathrm{El}$ control preventivo obligatorio es sencillo, por lo que es fácil justificar su celeridad. No

\footnotetext{
${ }^{68}$ Ribera (2007) p. 113.

${ }^{69}$ Por lo demás “¿qué sucede si no se ejercen adecuadamente los controles, sea porque no existió un estudio acabado o porque no se reúnen las mayorías parlamentarias? ¿Es consecuente con el principio de supremacía constitucional el sostener que un tratado internacional contrario a la Carta Magna pueda permanecer vigente en el orden jurídico chileno?”. Ribera (2007) p. 105.

${ }^{70}$ Favoreu (2001) p. 34; Alegre (2007) p. 20; Rousseau (2002) p. 54; Bon (1993) pp. 390 y 393; Moderne (1993) p. 416; Bordalí (2005) pp. 230-232.
} 
obstante, esto se debe vincular con la cantidad de trabajo a que esté sometido el órgano contralor y a su real capacidad, ya que si la sobrecarga de trabajo es demasiada, esta celeridad puede perderse, no obstante la sencillez del mismo control. ${ }^{71}$

A esta ventaja se responde con dos razones: en primer lugar, un control demasiado sencillo implica, en los hechos, una ausencia de control, como veremos. En segundo lugar, la razón por la cual el control es sencillo es inconveniente: la ausencia de principio de contradictoriedad y de experiencia en la aplicación de la ley. Ambos factores llevan a que, en los hechos, el órgano contralor tenga pocas herramientas de control, ya que no observa la ley en movimiento ni puede analizar los efectos de la misma, y tampoco tiene un problema o duda que se le presente. Así, no tiene argumentos de los cuales hacerse cargo, razón por la cual su sentencia estará exenta de motivación o fundamentos, como se verá en la sección II de este trabajo. ¿Puede considerarse que ha habido un control eficaz y completo si el acto en el cual éste se manifiesta (la sentencia) no está motivado?

4. Fortalece el principio de igualdad ante la ley, por cuanto evita un futuro control represivo concreto de efectos relativos. Este último suele generar diferencias en casos particulares, por cuanto hay situaciones similares que no son llevadas al TC y, por lo tanto, hacen eficaz el precepto legal que en casos análogos es declarado inaplicable. En cambio, el control preventivo es siempre erga omnes. ${ }^{72}$ Los efectos generales del control hacen que sus actos sean más igualitarios. Esta ventaja es bastante evidente, ya que la declaración de inconstitucionalidad producirá que la norma no ingrese al sistema de fuentes del Derecho, no siendo aplicable a nadie. Y si el TC la declara constitucional, entonces, una vez publicada, la ley entrará en vigencia respecto de todos.

Sin embargo, esta ventaja no es exclusiva del control obligatorio, ya que la igualdad es posible de conseguir cuando el TC es coherente con sus propios precedentes, o cuando elimina con efectos absolutos un precepto legal (art. 93, No 7 de la CPR). ${ }^{73}$ Lo importante es que el efecto relativo de las sentencias no signifique disparidad de criterios para resolver casos semejantes. Por lo demás, la experiencia

\footnotetext{
${ }^{71}$ Esta precisión se hace doblemente importante si se considera el considerable aumento de ingresos producido por la introducción de la inaplicabilidad como nueva atribución del TC, desde la entrada en vigencia de la reforma del 2005. De acuerdo a las memorias del propio TC, el año 2005 fueron dictadas 30 sentencias, mientras que las causas ingresadas el 2006 corresponden a 236. El 2007 esta cifra subió a 320 y el 2008 fue de 276. Véase TRIBUNAL CONSTITUCIONAL (2006) p. 16; y TRIBUNAL CONSTITUCIONAL (2009) p. 45.

${ }^{72}$ Moderne (1993) p. 416; Bordalí (2005) pp. 229-230.

${ }^{73}$ Ello es sin perjuicio de los enormes problemas que esta atribución ha generado. Sobre mi visión, véase Verdugo (2008).
} 
demuestra que en el mismo control represivo es posible encontrar precedentes que se respetan por el propio TC..$^{74}$

Por lo demás, el control preventivo obligatorio podría incluso generar desigualdades, por cuanto el mismo es ineficaz en el control por el respeto a los derechos fundamentales, como se verá más adelante. En efecto, como anota un importante autor " (...) entre la injusticia del control a priori que permite dejar sin sanción una ley que se manifiesta contraria al principio de igualdad desde el momento de su aplicación y la confusión del control a posteriori que permite la sanción, ¿no debería preferirse la confusión?"75

5. Utilidad para el respeto parlamentario del quórum de las LOC. Las materias propias de LOC deben ser aprobadas con un quórum especialmente alto. El control obligatorio garantiza que el TC examinará que se hayan reunido las mayorías correspondientes de acuerdo al mandato constitucional.

Este argumento presenta dos problemas: es parcialmente falso y es innecesario. Es parcialmente falso porque si el legislador estima que la norma en cuestión no es materia propia de LOC, entonces no la enviará al TC para que se ejerza el control, razón por la cual no existirá oportunidad para que se revise el cumplimiento del quórum, salvo que una minoría reclame, pero en ese caso la revisión procederá por el control eventual del art. 93, No 3 de la CPR y no por el control obligatorio. En realidad, los casos realmente problemáticos se producirán por esta vía, ya que si el legislador estima que la norma es propia de LOC, y la remite al TC, ella siempre habrá sido aprobada con las mayorías correspondientes. ${ }^{76}$ Sin perjuicio de lo anterior, existen casos en que el TC, en conocimiento de ciertas normas es-

\footnotetext{
${ }^{74}$ Véase, por ejemplo, los casos relativos al art. 116 del Código Tributario, que luego de numerosas declaraciones de inaplicabilidad, se declaró inconstitucional con efectos generales. VeRDUGO (2008). Otros ejemplos lo constituyen los famosos casos relativos a las isapres y a las normas que disponen solve et repete. Sobre isapres, véase, entre otros, el siguiente fallo: Tribunal Constitucional. Inaplicabilidad por inconstitucionalidad del artículo 199 del Decreto con Fuerza de Ley (Ministerio de Salud) No 1, de 2005. Rol No 1287-2008 (2009). En esta sentencia el TC utiliza sus propios precedentes en la materia. Sobre los casos solve et repete, véase, entre otras, la siguiente sentencia: Tribunal Constitucional. Inaplicabilidad por inconstitucionalidad respecto del inciso tercero del artículo 474 del Código del Trabajo. Rol No 1382-2009 (2009). En ella el TC cita de manera consistente sus numerosos precedentes en la materia. Además de los ejemplos citados, véase ZAPATA (1993) (2008) pp. 359-389.

${ }^{75}$ Rousseau (2002) p. 56.

${ }^{76}$ Esto ocurrió, a modo de ejemplo, con Tribunal Constitucional. Requerimiento de constitucionalidad promovido por 31 diputados y por la Presidenta de la República en relación a la actuación de la Cámara de Diputados en virtud de la cual se tuvo por desechado en general el proyecto de Acuerdo relativo a la Convención Interamericana sobre Desaparición Forzada de Personas. Rol No 1504-2009 (2009), pese a que finalmente el TC no acogió el requerimiento de los parlamentarios de la oposición, por estimarse que no se trataba de materias propias de LOC.
} 
pecíficas de un proyecto de ley, decide entrar a conocer de oficio de otras normas contenidas en el mismo proyecto, pese a que no han sido sometidas por la Cámara respectiva, debido a que forman parte del concepto de LOC que el propio TC ha definido. ${ }^{77}$ Sin embargo, este tipo de medidas no soluciona el problema mayor que ya anuncié: ¿qué sucede con los proyectos que nunca se envían al TC?

En segundo lugar, este control de quórum es innecesario puesto que las minorías cuentan con un mecanismo eficaz para protegerse de la mayoría simple que califique con quórums antojadizos las leyes, eludiendo la regla de super mayoría. En efecto, el control eventual es una excelente manera en que las minorías parlamentarias pueden, con el $25 \%$ de los parlamentarios de una cámara, ejercer un instrumento de protección para que se respeten los quórums. Si pensamos que estos quórums super mayoritarios están diseñados para proteger a las minorías, entonces no hay nadie mejor que ellas para decidir cuándo impetrar la causa ante el TC. Esta herramienta ya existe, en el art. 93, No 3 de la CPR. ${ }^{78}$

Como puede apreciarse, todas las ventajas descritas admiten alguna respuesta o, al menos, un matiz que relativiza su importancia. Este ejercicio argumentativo cuestiona las bases teóricas que sustentan el control obligatorio. Veamos ahora sus desventajas.

\section{Desventajas DEL CONTROL PREVENTIVO OBligatorio}

La primera desventaja del control preventivo obligatorio dice relación con la acusación formulada por la crítica escéptica, que ya tratamos (y relativizamos) en este trabajo. Las críticas pueden resumirse como sigue: 1.- Se corre el riesgo de producir un gobierno de los jueces; 2.- Se retrasa el procedimiento legislativo; 3.- Los problemas prácticos que ha generado en la jurisprudencia del TC; 4.- La ineficacia del control preventivo para adelantar el vicio de constitucionalidad. Varias de las desventajas que trataré admiten algún matiz o alguna respuesta. Sin embargo, el último de los puntos es, a mi juicio, el más concluyente.

1. Riesgo de producir un "gobierno de los jueces". ${ }^{9}$ Se ha dicho que "la tentación de un 'juez -dios', a quien un poder político debilitado exigiría decidir todo el futuro de la Nación, se convertiría en un peligro para la democracia”. ${ }^{80}$ Asimismo,

\footnotetext{
${ }^{77}$ Ello ha ocurrido, por ejemplo, con la sentencia del Tribunal Constitucional. Establece mecanismos de protección y de evaluación de los efectos producidos por el deterioro de la capa de ozono. Rol No 466-2006 (2006).

${ }^{78}$ Esta misma idea es desarrollada por ZAPATA (2008) pp. 440-442, aunque el autor no la hace necesariamente suya.

${ }^{79}$ Moderne (1993) p. 416.

${ }^{80}$ Renoux (1993) p. 447.
} 
se ha dicho que existe un riesgo de politización y de pérdida de legitimidad del órgano de control de constitucionalidad. ${ }^{81}$

Aunque no me parece que esta crítica sea muy evidente en la práctica, el riesgo de que el TC termine dirigiendo el proceso legislativo es un peligro eventual y factible. Sin perjuicio de ello, debe reconocerse, por un lado, que la ausencia de práctica respecto del mismo le quita importancia al argumento, el que incluso podría ser catalogado de excesivamente "alarmista"; y también, por otro lado, que de aceptar la procedencia de esta crítica, ella también sería aplicable al control eventual y al control represivo. Por ello, esta desventaja no sería exclusiva del control obligatorio.

2. Retraso en el procedimiento legislativo. ${ }^{82}$ A esto se contesta, como vimos en el apartado anterior, que el control obligatorio es expedito y rápido, y que esa dilación injustificada sólo se produciría por maniobras políticas de las minorías parlamentarias en el ejercicio de requerimientos que activen el control eventual o facultativo. ${ }^{83}$ Por lo anterior, esta crítica sólo sería válida en el control obligatorio si se consideran dos posibilidades: que el TC retrase el ejercicio del control por tener intereses involucrados, ${ }^{84}$ o porque la carga de trabajo es muy alta en relación con la capacidad para enfrentar todas sus tareas. De darse esta segunda posibilidad se estimula al TC a que altere sus tablas de ingreso para evitar las críticas que se puedan producir por un eventual retraso.

3. Los problemas prácticos que se han generado en la jurisprudencia del TC. ${ }^{85}$ Varios problemas se han producido. No es esta la ocasión para desarrollarlos a plenitud, aunque resulta importante hacer una breve mención.

Uno de estos problemas se traduce en la duda acerca de quién es la autoridad encargada de calificar la naturaleza orgánica constitucional de un precepto legal, lo que es muy importante para determinar la extensión de la atribución del propio TC. Todas las alternativas presentan problemas: si se dice que es el legislador, entonces éste tendrá una vía fácil para vulnerar la CPR, y si se dice que es el propio TC, entonces habría una intrusión judicial dentro del procedimiento legislativo. ${ }^{86}$ Todos

\footnotetext{
${ }^{81}$ Bordalí (2005) pp. 232-234. Véase también a Morton (1988) p. 95.

${ }^{82}$ Moderne (1993) p. 416.

${ }^{83}$ Morton (1988) p. 95.

${ }^{84}$ Ello ocurrió, por ejemplo, cuando el TC controló la modificación a su propia LOC. Véase Tribunal Constitucional. Ley No 17.997, Orgánica Constitucional del Tribunal Constitucional. Rol No 1288-2008 (2009). En este caso, el oficio de la Cámara de Diputados ingresó al TC con fecha 11 de diciembre del 2008, y el TC recién dictó sentencia con fecha 25 de agosto de 2009.

${ }^{85}$ Sobre esta materia, hay doctrina nacional que ha escrito de manera crítica. Véase, a PfeFfer (1998); ALDUNATE (2005); BuchHeIster et al (2005); ZAPATA (2008) pp. 432-448, entre otros.

${ }^{86}$ Pfeffer (1998) p. 262.
} 
los autores citados se hacen cargo del problema, pero yo destaco la interpretación que realiza Zapata, ${ }^{87}$ la que es a mi juicio coherente con las actas del Consejo de Estado. ${ }^{88}$ Es la CPR la que califica las normas orgánicas constitucionales, y el TC el intérprete de la CPR. Sin embargo, incluso esa interpretación presenta inconvenientes prácticos, como por ejemplo, que son las cámaras legislativas las que califican (en la práctica, son los presidentes de las comisiones legislativas); y que el TC no tiene atribuciones para solicitar que le sean remitidos ciertos proyectos. ${ }^{89}$

Otro problema que se plantea, vinculado estrechamente con el anterior es lo que sucede con las normas legales de naturaleza orgánica constitucional que no han sido enviadas al TC..$^{0}$ En estricto sentido, ellas gozarían de un problema de inconstitucionalidad de forma. ${ }^{91}$ ¿Se puede subsanar el vicio? ¿De qué manera? ¿Existe la posibilidad de repararlo? ¿Cómo? ¿Puede el control concreto analizar vicios de forma (que nunca se refieren a alguna aplicación)?

Por otra parte, también se puede producir el problema de que el TC tenga discrepancias internas respecto del ámbito de su control, lo que se genera por la existencia de diferentes visiones relativas al concepto específico de LOC. Así, una mayoría relativa que interprete el ámbito de control de una manera específica puede significar un precedente débil, susceptible de ser modificado fácilmente. Cuando ello ocurre, la señal orientadora que se le entrega al legislador es confusa, y las atribuciones del TC tienden a modificarse debido a la extensión o reducción de su ejercicio, el que depende justamente del desarrollo del concepto específico de la LOC que emplee en sus decisiones. Lo anterior es peligroso, ya que un cambio de criterio podría implicar que un precepto legal que no fue objeto de control adolezca actualmente de un vicio de constitucionalidad de forma, con lo cual una institución completa correría riesgo..$^{92}$ Ello no tendría lugar en un contexto en que el sello de constitucionalidad impida la procedencia del control represivo, lo que implicaría aceptar la legitimidad de una norma inconstitucional.

\footnotetext{
${ }^{87}$ Este autor hace un completo resumen de este problema. Véase ZaPATA (2008) pp. 435-448.

${ }^{88}$ En efecto, en la sesión 110, celebrada el 1 de julio de 1980 queda constancia que, luego de un breve debate "se produce acuerdo en cuanto a que es el Tribunal Constitucional el que tendría la última palabra". Véase el acta del Consejo de Estado en Arancibia et al (2008) p. 728.

${ }^{89}$ Pfeffer (1998) pp. 263-264.

${ }^{90}$ Esto ocurrió, por ejemplo, con la dictación del Código Procesal Penal. Ninguna de sus disposiciones fue enviada al control obligatorio, en circunstancias que el art. 77 de la CPR establece que son materias de LOC las que regulan la "organización y atribuciones" de los tribunales.

${ }^{91}$ Para Luz Bulnes, este caso también constituye una inconstitucionalidad de fondo. BulNES (1984) p. 234.

${ }^{92}$ Algo parecido ha sido denunciado en España, relativo a que hay normas legales que no se han tramitado como leyes orgánicas. Véase Alegre (2007) p. 23.
} 
Otro problema importante del control preventivo obligatorio dice relación con el sello de constitucionalidad, al que me referiré más adelante. ${ }^{93}$

4. El control preventivo es ineficaz adelantando los eventuales vicios de constitucionalidad. Así, este control no puede constituir una garantía de conformidad a la CPR y, en consecuencia, no otorgaría la certeza jurídica que se pretende..$^{94}$

Se ha dicho que el control preventivo "no puede anticipar exitosamente todo el potencial daño que se encuentra latente en leyes que todavía no han sido implementadas". ${ }^{95}$ Lo anterior se debe a que no sabemos con certeza cuáles son los efectos de las leyes en gestación, sino hasta que éstas efectivamente se aplican. ${ }^{96}$ Así las cosas, es poco probable que el control preventivo sea un buen "guardián de las libertades públicas contra el Parlamento". ${ }^{97}$

Este argumento se fortalece si se considera que las leyes modernas son complejas, y que muchas veces contienen cláusulas demasiado amplias o abstractas. Se trata de leyes que tienden a ser "vagas, incompletas, internamente contradictorias (...). las leyes no están hechas por una sola mente con una sola voluntad. Por el contrario, son decisiones colectivas que llegan a ser leyes porque atraen a una coalición de legisladores con diferentes visiones (...)" ${ }^{98}$ Imaginemos por ejemplo una ley que delegue en la autoridad administrativa la regulación de determinados aspectos, o una ley que contenga visiones contradictorias correspondientes a dos o más grupos de influencia, las que se incorporaron deliberadamente producto de una negociación política.

${ }^{93}$ Otro problema dice relación con el principio de inexcusabilidad que está consagrado en la LOC del TC. Para Aldunate, el problema radica en que la CPR no lo resuelve todo y, sin embargo, el TC debe ejercer su atribución de manera obligada, aun a falta de una norma constitucional que resuelva el problema sometido a su decisión. Véase AldunATE (2005) p. 122. Este autor llega a calificar el principio de inexcusabilidad como un "absurdo irredimible". Por otra parte, parte de la doctrina ha tratado el problema del "desmembramiento" de las LOC. Sobre este punto, que no profundizaré, véase BuCHHEISTER et al (2005).

${ }^{94}$ En efecto, el juez puede "no detectar una inconstitucionalidad". Moderne (1993) p. 416.

${ }^{95}$ Shapiro (1993) p. 477. Véase también Bordalí (2005) pp. 234-236.

${ }^{96}$ En este sentido, discrepo de la opinión de Alegre, para quien "Por mucho que se pueda objetar que el mejor 'banco de pruebas' para detectar la posible inconstitucionalidad de una ley es su aplicación, lo más habitual es que la inconstitucionalidad se manifieste sin necesidad de esperar los efectos prácticos de su aplicación, y el precio que supondría la espera podría ser demasiado alto". Alegre (2007) pp. 22-23. Son justamente los efectos prácticos los que dejan usualmente en evidencia la inconstitucionalidad.

${ }^{97}$ BeARdsley (1972) p. 439 (traducción propia).

${ }^{98}$ Shapiro (1993) pp. 478-479. Para este mismo autor, los problemas crecen debido a que el "lenguaje legal es vago e incompleto, de modo que cada uno de los grupos negociadores puede decir que refleja sus preferencias, aunque en sí mismo el lenguaje usado no tenga un compromiso definitivo con ninguna de las posiciones". SHAPIRO (1993) p. 478. 
Respecto de estas leyes, "no sabemos con exactitud qué significa y cuál será su efecto hasta mucho tiempo después de que sea promulgado. No sabemos el efecto operativo de la ley hasta que ha adquirido un número de años de historia administrativa posterior a su promulgación". ${ }^{99}$ Si no hay una experiencia de aplicación de la ley, no podemos saber cuáles son sus efectos reales. Esta situación se vuelve mucho más evidente tratándose del control de la ley respecto del respeto de los derechos fundamentales. ¿¿De qué manera podría el TC imaginar que se vulneran derechos fundamentales si no hay una hipótesis de aplicación de la misma? Parece difícil, aunque la experiencia francesa arroja casos excepcionales. ${ }^{100}$ Parece ser que el control preventivo sólo es posible (aunque improbable) en lo relativo al respeto por la parte orgánica de las $\mathrm{CPR}$, pero no respecto de principios, valores y derechos.

Es difícil (sino imposible) imaginar una aplicación hipotética prospectiva que sea contraria a la CPR, aunque de hecho puede aceptarse que se produzca. Si el TC tiene alguna duda no concluyente, probablemente eludirá la declaración de inconstitucionalidad, y hará un entendido interpretativo, siendo coherente con el principio de interpretación conforme y la doctrina de la deferencia al legislador. Esta práctica es muy frecuente en la jurisprudencia del Consejo Constitucional francés, ${ }^{101}$ aunque no es exclusiva del control obligatorio, ya que "todos los tribunales constitucionales europeos practican este tipo de decisiones interpretativas". ${ }^{102-103}$

Dicho entendido interpretativo será difícilmente aplicable. ¿Es verdaderamente vinculante? En opinión de un importante autor francés, al no existir un mecanismo que vincule a los jueces ordinarios con la aplicación de las interpretaciones gene-

\footnotetext{
99 Shapiro (1993) p. 479.

${ }^{100}$ Rousseau reconoce que "si en el momento de su concepción, una ley puede parecer perfectamente conforme a la Constitución, es posible que en el momento de su aplicación se muestre contraria a un principio constitucional, ya sea porque se aplica a situaciones nuevas o porque se ha reconocido valor constitucional a una nueva libertad o derecho o se le ha dado otra interpretación. En definitiva, no es sino en el momento de su aplicación cuando una ley puede atentar a los derechos y libertades de los individuos". Rousseau (2002) p. 55. Este mismo autor da un ejemplo de un caso de control concreto en sede preventiva, lo que es absolutamente excepcional. Véase Rousseau (2002) p. 93.

${ }^{101}$ Favoreu (2001) p. 35; Renoux (1993) p. 445. Para Favoreu, esto es una ventaja del control preventivo, ya que "favorece la eficacia de la propagación y de la difusión de las normas constitucionales". FAVOREU (2001) p. 34. Lo anterior sólo podrá ser cierto si la jurisprudencia interpretativa es conocida por los actores relevantes, y si éstos efectivamente la usan. El mismo autor reconoce esta debilidad y es optimista, ya que estima que esto cambiará "a partir del momento en que nuevas generaciones de juristas explotarán estas potencialidades". FAVOREU (2001) p. 35. Sobre la "ignorancia" y la educación constitucional como un obstáculo a las sentencias interpretativas, véase el mismo texto citado en las pp. 38-39.

${ }^{102}$ Rousseau (2002) p. 73.

${ }^{103}$ Una práctica similar es ejercida por la Contraloría General de la República mediante la toma de razón "con alcance". Véase Soto Kloss (2009) pp. 313-321.
} 
radas con ocasión del control constitucional, la "efectividad de la aplicación de las normas constitucionales puede no estar garantizada". ${ }^{104}$ No debemos olvidar que las sentencias interpretativas han sido severamente criticadas, y su constitucionalidad puesta en duda, ${ }^{105}$ no obstante que ésta sea una práctica frecuente en nuestro TC.

Por otro lado, si le damos al proyecto de ley declarado constitucional el sello de constitucionalidad, entonces se agrava el problema. El TC no pudo preveer la inconstitucionalidad, y luego, cuando ella se manifiesta, no puede hacer nada. Este punto representa una suerte de externalidad negativa del control preventivo, que amerita una dedicación especial en el apartado siguiente.

\section{UNA CONSECUENCIA INDESEABLE DEL CONTROL PREVENTIVO:}

\section{EL SELLO DE CONSTITUCIONALIDAD}

Cabe hacer presente que este sello de constitucionalidad fue ideado originalmente en un contexto de control eventual a requerimiento. ${ }^{106}$ Con este sello, se inhibe la posibilidad de que se ejerza el control represivo respecto de un precepto legal que fue declarado constitucional en el control preventivo por causa del mismo vicio. $^{107-108}$ Sin embargo, con la Carta de 1980 se introdujo en Chile la idea de las LOC (o de tratados internacionales que traten materias propias de LOC, lo que se incorporó con la reforma constitucional del 2005) y de las leyes interpretativas de la CPR, las que además de contar con un quórum superior de aprobación parlamentaria, deberán ser objeto obligatorio del control preventivo ante el TC.

${ }^{104}$ FAVOREU (1994) p. 112.

${ }^{105}$ No es esta la ocasión para desarrollar estas dudas. Véase Aldunate (2005) pp. 123-124.

${ }^{106}$ Véase a ANdrade (1971), pp. 590-605; Evans (1970), p. 139 y p. 142; Silva Cimma (2008), pp. 18-53; y Silva BASCUÑán (2003), pp. 176-178, entre otros.

${ }^{107}$ Debe recordarse que este sello de constitucionalidad fue derogado de la CPR con la reforma constitucional del 2005, de la Ley No 20.050, y reinsertado en la ley orgánica constitucional del TC el 2009. El propio TC no declaró la inconstitucionalidad de la modificación, permitiendo que ella se insertara en el sistema constitucional, sin perjuicio de un voto disidente de los ministros Vodanovic y Bertelsen (véase Tribunal Constitucional. Ley No 17.997, Orgánica Constitucional del Tribunal Constitucional. Rol No 1288-2008 (2009). Sobre el sello de constitucionalidad, véase mi trabajo en Verdugo (2009c).

${ }^{108}$ Las normas que actualmente regulan el sello de constitucionalidad se encuentran en la LOC del TC. Ellas disponen: art. 37, inc. $2^{\circ}$ : "Resuelto por el Tribunal que un precepto legal es constitucional, no podrá declararse inaplicable por el mismo vicio materia del proceso y de la sentencia respectiva". art. 45 bis: "Declarado por el Tribunal que un precepto legal impugnado de conformidad a este Párrafo es constitucional, no podrá ser declarado posteriormente inaplicable por el mismo vicio materia del proceso y de la sentencia respectiva". art. $47 \mathrm{G}$, inc. $1^{\circ}$, No 2: "Procederá declarar la inadmisibilidad en los siguientes casos: (...) $2^{\circ}$ Cuando la cuestión se promueva respecto de un precepto legal que haya sido declarado conforme a la Constitución por el Tribunal, sea ejerciendo el control preventivo o conociendo de un requerimiento, y se invoque el mismo vicio que fue materia de la sentencia respectiva". 
De esta forma, en las actas del Consejo de Estado se habla de una "especie de bendición general" a las LOC. ${ }^{109}$

En el control obligatorio no hay, en realidad, una controversia visible, ni intereses en juego. ${ }^{110-111}$ No hay una solicitud de inconstitucionalidad. De hecho, puede que ni siquiera exista una duda de constitucionalidad. Esto incluso hace sospechar, como vimos, acerca de la naturaleza jurisdiccional del control preventivo, ya que no hay partes, no hay intereses, no hay contienda y el TC no está llamado a adjudicar pretensiones. ${ }^{112}$ En verdad, el control obligatorio se parece más a la toma de razón de la Contraloría General de la República o al curso de un procedimiento no contencioso ante un juez ordinario, que a una causa controversial que se ventile frente a un juez llamado a dirimir un conflicto.

Por lo anterior, y como se demostrará en la sección II de este trabajo, es frecuente que el TC dicte una sentencia bastante sencilla, donde sin mayor fundamento declare que la norma sometida a su conocimiento es constitucional. ${ }^{113}$ Lo normal es que el TC haga un examen acerca de la naturaleza jurídica de la norma sometida a su control con el objeto de definir si corresponde o no ejercer su atribución, luego revise si se dio cumplimiento a los quórum que dispone la CPR para la aprobación parlamentaria, y en seguida declare constitucional la norma. Evidentemente que si el TC estima que la norma tiene algún vicio de constitucionalidad, deberá fundarlo, lo que no ocurre cuando estima que no existe una incompatibilidad entre alguna parte del proyecto de ley y la CPR. Por todo lo anterior, me parece que exigirle al TC que emita una sentencia que siempre esté fundada resulta excesivo, sino imposible de cumplir. Por ello, no puede suponerse que el TC haya "realizado y anticipado la aplicación de la norma y los juicios de constitucionalidad en función

\footnotetext{
109 Sesión 87, celebrada el 28 de agosto de 1979. Véase esta sesión en Arancibia et al (2008) p. 562. Cabe hacer presente, eso sí, que en la misma sesión hubo dudas acerca de la conveniencia de establecer este sello de constitucionalidad, el que finalmente queda explicado por Philippi en las propias actas de la siguiente manera: "La Corte Suprema no podrá conocer de un recurso de inaplicabilidad fundado en una causal legitimada por el Tribunal Constitucional; pero, en cambio, si el pronunciamiento de éste ha sido genérico, cabría el recurso de inaplicabilidad por causas específicas". Esta explicación fue acordada por la unanimidad de los miembros del Consejo.

${ }^{110}$ Véase Bordalí (2005) p. 217. “(...) la exclusión de los ciudadanos de la promoción del contencioso constitucional debe ser criticada, ya que se limita la información y la experiencia disponible para el tribunal, alejando la decisión de la realidad social donde tendrá aplicación”. BORDALí (2005) p. 218.

${ }^{111}$ Bon recuerda que el Consejo Constitucional incluso no acepta la representación de abogados. Este Consejo ha ido incluso más allá, declarando que las audiencias no son públicas. BoN (1993) pp. 391-392.

${ }^{112}$ Esta misma duda es planteada agudamente por AldunATE (2005) p. 123.

${ }^{113}$ La brevedad de las sentencias del control obligatorio son una realidad no sólo en Chile, sino también en Francia. Para un autor, esto ya es verdadero estilo propio de las decisiones del Consejo Constitucional. BeARdsley (1972) p. 435.
} 
de la Constitución y ha descartado todos los vicios posibles." ${ }_{14}$ Ello me parece absurdo ya que, y como dice el profesor Aldunate, "la naturaleza abstracta del control preventivo (...) favorece una extensión ad infinitum de las materias que un órgano jurisdiccional (...) puede estimarse legitimado para resolver." 115

Por supuesto, existen excepciones en que el TC hace un análisis más profundo. Sin embargo, y como veremos, se trata sólo de excepciones que no alteran la práctica habitual.

De aceptar la existencia del sello de constitucionalidad (que está vigente, pese a su evidente inconstitucionalidad ${ }^{116}$ ), debemos preguntarnos: ¿en qué casos la sentencia que declara la constitucionalidad del precepto imprimirá dicho sello? Hay varias alternativas de respuesta: 1 . La sentencia debe ser fundada; 2 . La sentencia no debe ser fundada, pero debe especificar con precisión el precepto legal que se declara constitucional; 3. La sentencia sólo debe realizar una declaración general e indirecta de constitucionalidad, sin fundar mayormente la decisión.

1. Si se considera que la sentencia debe ser fundada respecto del precepto específico que declara constitucional, ${ }^{117}$ entonces se imprimirá el sello de constitucionalidad en el precepto legal cuando el control obligatorio cumpla con este deber. Sin embargo, ésta no es la práctica más frecuente en la actividad del TC. ${ }^{118}$ Volveré sobre este punto más adelante.

Sin perjuicio de lo anterior, hay que tener presente que esta situación se puede producir en la práctica con las sentencias que, declarando la constitucionalidad de un precepto, realizan un alcance interpretativo de la misma. De esta manera, el TC evita declarar la inconstitucionalidad en el entendido de que la norma tiene un significado compatible con la CPR..$^{19-120}$ Normalmente, estas sentencias están fundadas, por lo que caben en esta primera hipótesis. Sin embargo, si estos

\footnotetext{
${ }^{114}$ Ministerio Secretaría General de la Presidencia (2000) p. 400.

${ }^{115}$ Aldunate (2005) p. 121.

${ }^{116}$ Sobre este punto, véase mi trabajo en Verdugo (2009c).

${ }^{117}$ Esta pareció ser la posición de SiLVA y SiLVA (1988) p. 330, en cuanto a los requisitos para que se genere el sello de constitucionalidad. Asimismo, ésta parece ser la concepción del Consejo de Estado. Sesión 87, celebrada el 28 de agosto de 1979. Véase esta sesión en ArANCiBiA et al (2008) p. 562.

${ }^{118}$ No obstante, esta es la posición de Pfeffer (1998) p. 261. Este autor plantea incluso que el TC debe hacerse cargo de las dudas que se planteen en la tramitación legislativa del proyecto de ley en cuestión, lo que, a mi juicio, es un exceso.

${ }^{119}$ Sobre las sentencias interpretativas, puede verse, entre otros trabajos, a ZAPATA (1994) pp. 120-123; y a De La Cruz (2007).

${ }^{120}$ Para el profesor Aldunate, las sentencias interpretativas son ilegítimas, por cuanto convierten al TC en un legislador. AldunATE (2005) pp. 123-124.
} 
entendidos del TC no se respetan, habrá un grave problema. En otras palabras, existirá una interpretación con sello de constitucionalidad, pero no una norma con sello de constitucionalidad, lo que podría traer grandes confusiones a los obligados por la norma. En consecuencia, cuando se presente una acción de inaplicabilidad, el TC deberá analizar si puede o no conocer de dicha acción en el entendido en que la interpretación que se esté utilizando sea diferente a la utilizada en el control preventivo. Lo anterior es poco factible, ya que en el procedimiento de inaplicabilidad el TC aún no sabe qué interpretación utilizará el juez de la gestión pendiente, debiendo hacer un análisis prospectivo donde adelante la tarea del juez del fondo. Por consiguiente, el TC debería entender que la única interpretación posible es que la sostuvo en su sentencia del control preventivo, lo que lo haría rechazar la acción de inaplicabilidad. Sin embargo, puede que el juez del fondo tenga una opinión diferente (y desconocida para el TC), lo que nos lleva a una pregunta muy difícil de contestar: ¡es vinculante la parte considerativa de la sentencia del control preventivo? ¿'Se incorpora a la ley interpretada? ${ }^{121}$

2. Si la sentencia no es fundada, pero declara específicamente la constitucionalidad de preceptos particulares, podría entenderse que existe sello de constitucionalidad. ${ }^{122}$ Este parece ser el caso más frecuente en materia de control preventivo obligatorio. ${ }^{123-124}$

Sin embargo, se trata de casos en que el TC no motiva su sentencia (y tampoco tiene por qué hacerlo, como veremos). Entonces, se trata de una norma que goza de sello de constitucionalidad, pero con un grave problema: como no conocemos los fundamentos de la sentencia (no se expresan en el fallo, lo que no significa que no existan) desconocemos la manera en que se realizó el control. Es más, si el TC no tuvo una mínima duda de constitucionalidad, puede que ni siquiera haya habido control, lo que no puede saberse. En este sentido, el sello de constitucionalidad se

\footnotetext{
${ }^{121}$ Cabe hacer presente que el TC ha desconocido sus propios precedentes, siendo estos recientes. Al respecto, puede verse un ejemplo en la sentencia del Tribunal Constitucional. Artículo 161, № 10 del Código Tributario. Rol No 1246-2008 (2009). Véase en especial la indicación del ministro Carmona, quien hace presente esta situación.

${ }^{122}$ Véanse los ejemplos que da el profesor Fernández (1997) pp. 15-16.

${ }^{123}$ Algunos ejemplos recientes de lo anterior: Tribunal Constitucional. Permite el voto de los habitantes de la localidad de Chaitén en las elecciones presidenciales y parlamentarias. Rol No 1503-2009 (2009): "SE DECLARA: que el artículo único del proyecto remitido es constitucional"; Tribunal Constitucional. Faculta al Fisco para comprar y vender propiedades particulares afectadas por situaciones de catástrofe. Rol No 1489-2009 (2009): "SE DECLARA: que el inciso final del artículo $7^{\circ}$ del proyecto remitido es constitucional"; Tribunal Constitucional. complementa la ley que establece un nuevo asiento para el Juzgado de Letras de Chaitén. Rol No 1440-2009 (2009): "Se declara: que los artículos 10, $2^{\circ}$ y $4^{\circ}$ del proyecto remitido son constitucionales".

${ }^{124}$ Para algunos, ésta es una característica propia de la sentencia del TC. Véase Ministerio Secretaría GeNeral de La Presidencia (2000) p. 394.
} 
podría volver perverso. El TC nunca se puso en hipótesis concretas de aplicación de la norma que podrían ser inconstitucionales, porque eso no se puede saber en el momento del control preventivo (tampoco está llamado el TC a ponerse en esas hipótesis de aplicación concreta). Sin embargo, se estaría impidiendo la declaración de un control represivo respecto de dicha norma, dejando a las personas en una eventual indefensión frente al legislador. Si el TC no imaginó hipótesis de aplicación, entonces no es coherente que se inhiba el control sobre ellas, razón por la cual lo conveniente es eliminar el sello de constitucionalidad.

3. La tercera posibilidad es que el TC sólo realice una declaración general (o indirecta) de constitucionalidad, sin mayores fundamentos, y sin especificar el precepto específico que se declara constitucional. Por ejemplo, que el TC diga "El resto de los preceptos contenidos en el proyecto de ley no son contrarios a la Constitución", o "el proyecto de ley sometido al control preventivo es constitucional". ${ }^{25}$ En este caso no existe sello de constitucionalidad respecto de los preceptos específicos de que se trate. Esto hace cuestionar la utilidad de la norma que dispone el sello de constitucionalidad.

Fuera de las tres posibilidades de sentencia del TC, hay que preguntarse: ¡en qué casos el TC optará por una o por otra? La decisión será importante para definir la extensión de sus propias atribuciones de control represivo, por lo que no es inocuo lo que finalmente determine.

Lo anterior me parece peligroso e inconveniente. Ello implica darle una amplia discrecionalidad a los jueces para decidir en qué casos le imprimen la protección a la ley y en qué casos no, lo que parece ser una tarea más propia del Constituyente.

En conclusión, el sello de constitucionalidad agrava las razones que demuestran la inconveniencia del control preventivo obligatorio.

En la siguiente sección, intentaré mostrar lo señalado en este capítulo en la práctica del TC, ilustrando acerca de cómo el TC ha enfrentado en los últimos años los desafíos que plantea el control preventivo obligatorio. El enfoque estará basado en el aporte que el mismo efectúa a la dogmática jurídica, según explicaré.

\section{SECCIÓN II}

\section{Dogmática constitucional en las SENTEnCias del Tribunal Constitucional EMANADAS DEL CONTROL PREVENTIVO Y OBLIGATORIO DE CONSTITUCIONALIDAD}

En esta sección intentaré demostrar que el aporte que realizan las sentencias del TC, emanadas del control obligatorio es escaso en términos de dogmática.

\footnotetext{
${ }^{125}$ Esto ocurrió, por ejemplo, en Tribunal Constitucional. Ley No 17.997, Orgánica Constitucional del Tribunal Constitucional. Rol No 1288-2008 (2009), punto 17 de la parte resolutiva.
} 
Lo anterior se explica por tres razones que paso a resumir: en primer lugar, el TC no está obligado jurídicamente a fundar las sentencias de constitucionalidad en este tipo de control, de acuerdo a la naturaleza de esta atribución. En segundo lugar, es poco factible que exprese mayores fundamentos. En tercer lugar, la evidencia empírica ratifica una tendencia natural en este tipo de control constitucional.

La relevancia de esta sección dice relación con el valor que tiene la jurisprudencia constitucional en nuestro sistema de fuentes del Derecho. ${ }^{126}$ Si puede probarse que la jurisprudencia no comunica una expresión acerca de lo que el Derecho es, o que lo hace escasamente, entonces podremos discutir su verdadera utilidad.

La idea de aportar a la dogmática se vincula con una aproximación económica de la justicia constitucional. En esta perspectiva, sólo se justifica el financiamiento público en la medida en que el sistema financiado sea capaz de generar bienes públicos en un sentido económico. ${ }^{127}$ Los bienes públicos que la justicia constitucional está llamada a generar son dos: el control del poder político (lo que lleva a la protección de los derechos fundamentales) y la información acerca del sistema normativo. ${ }^{128-129-130}$ Si no hay fundamentación de las sentencias, entonces difícilmente puede saberse si el control constituye un límite al ejercicio del poder, por lo que el primer bien público puede cuestionarse. ${ }^{131}$ Por lo demás, si nos remitimos a la ineficacia del control obligatorio en la protección de los derechos fundamentales, según ya argumenté en este trabajo, podemos ver que este bien público se

\footnotetext{
${ }^{126} \mathrm{El}$ valor de la jurisprudencia constitucional es frecuentemente realzado por la doctrina. Por esta misma razón, existen varios autores que incluso han hablado de un "precedente constitucional". Entre ellos, véase a Zapata (1993) (2008) pp. 359-389; Peña (2006) y ZúÑiga (2006).

127 VARGAS et al (2001) p. 29.

${ }^{128}$ VARGAS et al (2001) p. 39. Podría decirse que la justicia en general está llamada a reducir la incertidumbre, lo que también es aplicable, desde luego, a la justicia constitucional. Véase VArGaS et al (2001) p. 25.

${ }^{129}$ La importancia de este bien público recuerda las palabras de Posner, sin perjuicio de que la opinión de este autor está contextualizada en el sistema de precedentes anglosajón: "Desde el punto de vista económico, el cuerpo de precedentes es un área de la ley, es un acervo de bienes de capital; específicamente, un acervo de conocimientos que rinde servicios durante muchos años a disputantes potenciales bajo la forma de información acerca de obligaciones legales". PosNer (2007) p. 836.

${ }^{130}$ Cabe precisar que la información también puede ser concebida como una externalidad positiva de las sentencias particulares, y no necesariamente como un bien público, ya que al resolver un caso particular con beneficios individuales (bien privado en el lenguaje de los economistas) genera información para todo el sistema.

${ }^{131}$ Por otra parte, si no hay fundamentación de las sentencias, difícilmente pueden someterse las mismas a la crítica académica. Ello, sin perjuicio de que los costos de la crítica profesional sean moderados para los jueces (POSNER -2007- p. 838). La fundamentación es importante, ya que (entre otras cosas) permite tener mayor certeza acerca de la calidad del trabajo que se desarrolla en la jurisprudencia. Si no sabemos cuál es ese trabajo (por la falta de información), menos sabremos acerca de si el mismo se desarrolla de buena manera.
} 
encuentra, a lo menos, en un estado crítico. ${ }^{132}$ Por otra parte, si las sentencias no se fundamentan, entonces su capacidad para entregar información disminuye. Si bien es cierto que la sola resolución de la sentencia ya tiene la capacidad de constituir una información para los actores del sistema, ella no será, probablemente, suficiente. En consecuencia, este bien público difícilmente se generará. Así, la mantención del sistema de control obligatorio perdería justificación desde la perspectiva económica.

Como los elementos que definen lo anterior se vinculan a la fundamentación de las sentencias y, finalmente, con la dogmática jurídica que se genera producto de dicha fundamentación, cabe hacer presente que lo dicho en torno al aporte a la dogmática, debe ser también considerado como aporte a esta importante aproximación. Así, si se prueba que la pobreza del aporte a la dogmática, estaríamos acercándonos a probar la pobreza en el aporte a la generación de bienes públicos, lo que hace doblemente interesante este análisis.

En esta sección seguiré el siguiente orden:

Como primera cuestión, me referiré brevemente al concepto de dogmática, definiendo de qué manera una sentencia judicial es capaz de aportar al desarrollo de ella. La idea de este apartado es construir una idea precisa acerca de los elementos que se requieren para que una sentencia aporte a la dogmática. Esto es esencial para mi trabajo, ya que si no se define esto, existirán múltiples caminos que harían discutible la defensa de mi hipótesis.

En segundo término, y según ya adelanté en la sección anterior, examinaré si el TC se encuentra jurídicamente obligado a motivar (o fundamentar) sus sentencias en este tipo de control. Veremos que esto admite ciertos matices que es necesario precisar. Si las sentencias carecen de motivación, no puede existir aporte a la dogmática. De allí que sea importante las razones por las cuales, a mí entender, esta obligación no existe. Esta posibilidad jurídica reconoce que igualmente el TC puede fundamentar las sentencias en su práctica, sin perjuicio de que no se encuentre en el imperativo de hacerlo.

Por lo anterior, en tercer lugar, y ya habiendo demostrado que no existe la obligación de fundamentar las sentencias que son objeto de este trabajo, veré si existe la posibilidad de que el TC (y no obstante no haber un imperativo jurídico) fundamente de igual forma sus sentencias. En este apartado, indicaré las razones que me llevan a pensar que es poco probable (o poco factible) que el TC fundamente sus decisiones. Fundamentalmente, estas razones se vinculan con la naturaleza del control preventivo obligatorio. La idea esbozada en este párrafo será tratada en conjunto con la idea del párrafo anterior, pese a que se trata de

132 Además, véase VARGAS et al (2001) p. 40. 
cuestiones diferentes. Ambas cosas están inevitablemente comunicadas a raíz de la naturaleza especial del control obligatorio.

En cuarto lugar, demostraré que lo señalado en los párrafos anteriores se verifica en la práctica del TC. Así, definiré una muestra significativa de fallos del TC provenientes del ejercicio de este control, y describiré lo que ha sucedido.

\section{SentenCias JUdiCialeS Y APORTE A LA DOGMÁTICA JURÍdicA}

En este capítulo extraeré los elementos comunes de la doctrina que pueden observarse del concepto de dogmática. Así, estaré en condiciones de establecer cuándo un texto jurídico constituye o no un aporte a la misma. Luego, examinaré de qué manera un documento jurídico específico (la sentencia judicial) colabora con la dogmática.

Si se analizan diversos conceptos de dogmática entregados por la doctrina ${ }^{133^{-134}}$, se pueden extraer las siguientes inferencias: 1. El Derecho es el objeto de estudio de la dogmática. 2. La dogmática visualiza al Derecho como un sistema unitario, coherente y sistemático. 3. Los enunciados que la misma expone deben ser armónicos, y carecer de contradicciones. 4. La dogmática hace un esfuerzo por explicar de manera racional los enunciados jurídicos.

¿En qué caso un texto o documento jurídico constituye un aporte a la dogmática? Cuando estudia y explica el Derecho de manera racional, coherente y sistemática. Luego, no será un aporte a la dogmática un texto jurídico que se limita a reproducir el Derecho, o que entrega respuestas contradictorias entre sí, o que agrega elementos no relevantes para el Derecho, o que no utiliza la razón (o razones) para fundamentar la explicación respectiva.

La sentencia judicial es un texto o documento jurídico que tiene ciertas particularidades propias que las separan de otros textos provenientes de la doctrina

${ }^{133}$ Véase en especial la opinión de Aldunate (2008) pp. 103-108.

${ }^{134}$ Para Hübner la "Dogmática jurídica (la Ciencia del Derecho propiamente tal) tiene por objeto dar una exposición unitaria y coherente del Derecho Positivo en vigencia. O sea, como observa Recaséns Siches, su misión se reduce a reproducir los derechos vigentes, explicándolos y sistematizándolos." HüBNER (1984) pp. 47-48. Para Squella, "El derecho en sentido objetivo, esto es, como conjunto de normas, puede ser constituido en objeto de estudio (...). Pues bien: a ese saber o conocimiento (...) se le acostumbra llamar (...) 'dogmática jurídica'. (...) conviene reservar la palabra 'derecho' para aludir al ordenamiento jurídico y 'ciencia del derecho' para designar al saber que es posible constituir acerca del ordenamiento. (...) el 'derecho', en cuanto orden de la conducta humana, está compuesto por normas; en cambio, la llamada 'ciencia del derecho' lo está por enunciados o proposiciones acerca de las normas (...)”. SQuella (2004) p. 118. Para Jaime Williams la dogmática se refiere a la "ciencia jurídica”, y esta última "(...) puede ser entendida como el conocimiento racional y sistemático del derecho positivo (...). El objeto de la ciencia jurídica sería, entonces, el derecho positivo vigente en una determinada sociedad y en una época dada". WilLIAMS (1999) pp. 434-431. Para Theodor Viehweg, la dogmática es una "opinión jurídica racionalizada". Para que exista dogmática, "(...) tiene que haber, en todo caso, por lo menos un dogma fundamental o varios dogmas fundamentales conciliables entre sí (...)”. VIEHWEg (1991) p. 16. 
o de una ley interpretativa. Sin embargo, ello no significa que una sentencia no pueda constituir un aporte a la dogmática. De hecho, es frecuente que lo haga, en tanto es una importante fuente (práctica) del Derecho.

La característica esencial de la sentencia judicial radica en el hecho de que ella resuelve o dirime un asunto mediante el ejercicio de una atribución jurisdiccional que realiza un tercero imparcial. ¿Puede aportar a la dogmática? La respuesta es positiva en la medida en que ella entregue razones que justifiquen su decisión y en que esas razones persigan explicar el Derecho de manera coherente.

Así, el estudio de una sentencia contribuirá al conocimiento del Derecho como sistema. Ello trae ciertos beneficios para el estudiante de la sentencia: podrá extraer inferencias relativas al comportamiento de los tribunales, pudiendo deducir con cierto grado de predicción lo que harán éstos en el futuro. Lo anterior dependerá de la repetición constante que la propia sentencia haga respecto de otras sentencias. Así, las opiniones racionalizadas de los tribunales, en tanto se repitan constantemente, generarán jurisprudencia. Esto trae ciertos beneficios adicionales: seguridad jurídica e igualdad en la aplicación del Derecho, entre otros.

Si las sentencias no expresan dogmática, entonces difícilmente pueden replicarse en un futuro, ya que no se conocen las razones que llevaron a la misma a adoptar la decisión específica. Por lo tanto, mientras menos dogmática generen las sentencias, menos valiosas e influyentes serán las mismas.

Las sentencias emanadas del control obligatorio de constitucionalidad tienen una característica que las separa del resto, como ya hemos visto: no hay conflicto, ni partes, ni requerimiento. Luego, no se dirime una controversia, sino que sólo se realiza un control necesario jurídicamente. Se trata, reiterando mi posición, de un control jurídico, pero no jurisdiccional. Algo parecido a lo que ocurre con la toma de razón de la Contraloría General de la República, aunque muy distinto en tanto a la naturaleza del órgano contralor: en un caso un ente administrativo y en el otro una autoridad con competencia de legislador negativo.

Este tipo de control es preventivo. En otras palabras, se persigue impedir un conflicto futuro. La idea no es adjudicar derechos ni satisfacer intereses subjetivos, sino solamente efectuar un control de la legitimidad constitucional de la norma que ha sido sometida por mandato de la CPR al análisis del TC.

Distintos serán los efectos de las sentencias dependiendo de la decisión que contiene. Así, si el TC determina que la norma es inconstitucional, la misma no se inserta en el sistema jurídico. En este caso es necesario que exista un fundamento en la sentencia, ya que se está impidiendo que el legislador haga su tarea. El fundamento de la misma será importante para el futuro trabajo del legislador, haciendo que los beneficios de la dogmática generada en este caso sean evidentes. Independientemente que el legislador se vincule o no por los precedentes produ- 
cidos en estos casos (lo que es discutible) el aporte a la dogmática es innegable, por la necesidad de explicar racionalizadamente el Derecho Constitucional que impedirá el nacimiento de la norma.

Distinto será el caso en que el TC declare que el precepto sometido a su conocimiento es constitucional, permitiendo con ello que el acto producido en las cámaras legislativas siga su curso para, finalmente, insertarse en el sistema jurídico. En este caso se altera sustancialmente la manera en que el TC fundamenta sus decisiones, razón por la cual el aporte a la dogmática es escaso. Este análisis requiere del examen de muchos matices que explicaré.

Como puede apreciarse, el vínculo entre aportar a la dogmática y la fundamentación razonada y coherente de las decisiones es muy importante. Por eso mismo, en el próximo apartado examinaré si existe la obligación jurídica de que el TC motive sus sentencias. Luego, se verá si, aun cuando este imperativo no exista, es probable o no que en la práctica se haga.

\section{NECESIDAD Y FACTIBILIDAD DE QUE EL TC}

\section{FUNDAMENTE LAS SENTENCIAS EN EL CONTROL PREVENTIVO OBLIGATORIO}

Debemos preguntarnos si existe la obligación de que el TC fundamente sus sentencias en el ejercicio del control preventivo obligatorio. La respuesta, en general, es negativa: no es necesario que el TC funde sus sentencias.

Una precisión previa: en general, me parece que todos los actos estatales deben ser fundados, ya que de lo contrario podrían tener problemas relacionados con el principio de interdicción de arbitrariedad. ${ }^{135}$ En particular, las sentencias deben ser motivadas (además) como una expresión de los principios reconocidos en el art. 19, No 3 de la CPR. Sin embargo, debe reconocerse la posibilidad de que existan actos donde los fundamentos no estén expresados. Esto es reconocido por el propio Eduardo Soto Kloss. ${ }^{136}$ Muy gráfico resulta el ejercicio de la toma de razón pura y simple por parte de la Contraloría General de la República, la que

${ }^{135}$ Soto Kloss (2009) pp. 353.

${ }^{136}$ Sin perjuicio de que su análisis lo realiza con ocasión del acto administrativo, me parece útil traer a colación sus palabras: “(...) si bien todo acto para que sea válido debe responder a un motivo y ha de poseer una fundamentación racional (...) no siempre el ordenamiento exigía expresamente la explicitación de ellos en la decisión que se dicte (...) sino cuando le parecía necesario (...). Hoy, en razón de la Ley No 19.880, todo D [decreto] o R [resolución] debe ser motivado (art. 41, inc. 4º), con aplicación supletoria. Lo que sí es exigido siempre -tanto por la Contraloría General como por los tribunales- es la expresión de las normas (...) que habilitan al autor". Sото KLoss (2009) p. 351. Implícitamente, Soto Kloss admite que la supletoriedad de la Ley No 19.880 permite la posibilidad de que la ley disponga otra cosa. Volviendo al TC, su LOC dispone expresamente que no debe fundamentar las sentencias de constitucionalidad simple en el caso del control preventivo obligatorio. Cabe hacer presente que señalar estas normas es una práctica que nunca ha estado en duda en el control obligatorio. 
básicamente consiste en un timbre estampado en el documento que contiene el acto administrativo, tal como lo expone el destacado administrativista que citamos. ${ }^{137}$

Para los procedimientos generales que se llevan adelante en el TC, existe el mandato legal de que éste fundamente las sentencias que dicta. En este sentido, el art. 31 de la LOC del TC, ubicado en las normas generales del procedimiento de dicho tribunal, dispone que las sentencias del TC deben cumplir con los requisitos del art. 170 del Código de Procedimiento Civil. Se agrega a ello que los ministros disidentes deben hacer constar su opinión.

La remisión que la LOC del TC hace al Código de Procedimiento Civil implica la inclusión de todos los requisitos de las sentencias provenientes del Poder Judicial, tales como "Las consideraciones de hecho o de derecho que sirven de fundamento a la sentencia" (art. 170, No 4) y "La enunciación de las leyes, y en su defecto de los principios de equidad, con arreglo a los cuales se pronuncia el fallo" (art. 170, No 5, del Código de Procedimiento Civil). En atención a lo anterior, puede sostenerse que, en términos generales, el TC debe motivar sus decisiones.

Sin embargo, lo anterior tiene importantes matices efectuados por la misma LOC del TC, tratándose del control obligatorio de constitucionalidad. En efecto, en el párrafo respectivo, el art. 35, incs. 3, 4, 5 y 6, de la LOC del TC, dispone que:

"Resuelto por el Tribunal que el proyecto respectivo es constitucional, y no habiéndose producido en la etapa de discusión de dicho proyecto la situación prevista en el inciso final del artículo anterior, ${ }^{138}$ el Tribunal así lo declarará y su Presidente lo comunicará a la Cámara de origen.

En todo caso la resolución deberá ser fundada si se tratare de una ley interpretativa de la Constitución.

Si el Tribunal encontrare que el proyecto es constitucional y se hubiere producido la situación prevista en el inciso final del artículo anterior, el Tribunal deberá declarar la constitucionalidad del proyecto fundándola respecto de los preceptos que, durante su tramitación, hubieren sido cuestionados.

Si el Tribunal resolviere que uno o más preceptos del proyecto son inconstitucionales deberá declararlo asi mediante resolución fundada, cuyo texto integro se remitirá a la Cámara de origen".

De esta manera, y tratándose del control de constitucionalidad de una LOC (y no de un control eventual, o de una sentencia de inconstitucionalidad, o de una ley interpretativa), no es necesario que el TC exprese los fundamentos de las

${ }^{137}$ Soto KLoss (2009) p. 315.

${ }^{138}$ Se refiere al control eventual derivado de algún requerimiento de inconstitucionalidad. En este caso se ejercerá la atribución del art. 93, $\mathrm{N}^{\circ} 3$ de la CPR. Es evidente que el nivel de fundamentación en este caso es diferente, en tanto existe una manifiesta "duda" de constitucionalidad. 
sentencias "si no se ha suscitado cuestión de constitucionalidad durante su tramitación y el proyecto no le merece reparos". ${ }^{139}$ En otras palabras, las sentencias que declaran la conformidad con la CPR de un precepto legal que ha sido sometido a su conocimiento producto del control preventivo obligatorio, pueden ser infundadas en su expresión considerativa (sin perjuicio de que puedan existir fundamentos que no estén expresados). ${ }^{140}$ Ello no significa que carezcan de fundamentos, sino simplemente que ellos no están indicados explícitamente en la parte considerativa de la sentencia. Esta es la única manera de entender la norma si consideramos que, por mandato directo de la CPR, “(...) El Tribunal (...) fallará de acuerdo a Derecho. (...)” (art. 92, inc. 50, de la CPR).

Entonces, la LOC exime al TC de motivar sus sentencias en estos casos. Por consiguiente, quien quiera alegar que la falta de fundamentación de las mismas es inconstitucional, debiera también plantear la inconstitucionalidad de esta LOC. Sin perjuicio de que puedan existir dudas, esta norma está vigente.

Lo contrario ocurre si el TC declara la inconstitucionalidad de algún precepto propio de LOC ya que, en este caso, el TC debe justificar debidamente su decisión. ${ }^{141}$ Entre nosotros, lo mismo suele ocurrir tratándose de sentencias que, con el objeto de declarar la constitucionalidad del proyecto, interpretan el mismo en un sentido conforme a la $\mathrm{CPR}$, rechazando otras posibilidades de interpretación. ${ }^{142}$ Ello se debe a una razón evidente: si el TC opta por una interpretación específica para eludir la declaración de inconstitucionalidad, debe explicar el procedimiento lógico por el cual llegó a establecer dicha interpretación. Si no lo hiciera, entonces la interpretación sería antojadiza. Así, admitiendo que existen varias maneras de interpretar la norma, el TC elije la que mejor recoge el principio de supremacía constitucional. Lo anterior sólo puede entenderse en el contexto de una sentencia motivada. Es discutible el aporte que el TC realiza a la dogmática en este tipo de casos, ya que habrá que distinguir si el TC hizo razonamientos para llegar a la interpretación que sostiene, o si simplemente la esboza de manera general.

${ }^{139}$ Silva Bascuñán (2003) p. 61. A esta misma conclusión llega Ríos (1983) p. 42.

${ }^{140}$ Una opinión diferente es sostenida por Pfeffer: "de resolverse que el proyecto de ley es constitucional, el Tribunal, en su sentencia, deberá expresar de manera precisa, el razonamiento que lleva a dicha conclusión, debiendo hacerse cargo de modo especial de las argumentaciones que, durante el debate en las Cámaras, se plantearon como dudas de constitucionalidad". Pfeffer (1998) p. 261. Discrepo de esta visión por las razones dadas en este trabajo, aunque ignoro los argumentos en que se funda.

${ }^{141}$ Aldunate sostiene que las "inconstitucionalidades evidentes (...) constituyen o deberían constituir una minoría”. AldunAte (2005) p. 124. Por consiguiente, lo normal es que las normas sean constitucionales, o que las inconstitucionalidades no sean tan evidentes, lo que abre las puertas a la dictación de sentencias de interpretación conforme, a las cuales ya me referí en este trabajo.

${ }^{142}$ Sobre este tipo de sentencias, véase entre otros a De LA CRUZ (2007) y ZaPATA (1994). 
En el caso del control de leyes interpretativas de la CPR, el TC siempre debe fundar su declaración de constitucionalidad, de acuerdo al mandato legal ya reproducido en párrafos anteriores. Esto se debe a la especial trascendencia que tiene una norma interpretativa de la CPR. ${ }^{143}$ Sin embargo, y como ya lo advertimos, son muy poco frecuentes los casos en que se dictan leyes interpretativas de la CPR, ${ }^{144}$ razón por la cual el control preventivo obligatorio se centra casi exclusivamente en la evaluación constitucional de LOC y de tratados internacionales que contengan materias propias de LOC.

Como ya lo adelanté, podría pensarse que las sentencias deben estar motivadas por razones constitucionales derivadas del debido proceso, la igualdad ante la justicia (art. 19, No 3 de la CPR) y ausencia de arbitrariedad (art. 19, No 2 de la $\mathrm{CPR})$. Se trata de un argumento derivado de los derechos esenciales de quienes intervienen en el proceso invocando intereses que, estiman, deben protegerse. De aceptarse este argumento, no podría defenderse la constitucionalidad de la norma que exime al TC de motivar sus decisiones. Sin embargo, estimo que este argumento tiene un importante matiz en el caso del control obligatorio, ya que al no existir partes, no hay derecho esencial que invocar y, por consiguiente, no puede afectarse ningún derecho al debido proceso. Ello, por la obvia razón de que no puede protegerse lo que no existe.

Como se ilustrará, lo frecuente en la práctica es que el TC utilice la norma reproducida y explicada y declare la constitucionalidad del proyecto sometido a su control mediante una declaración que no contiene mayores consideraciones. Ello ocurre, como ya lo dije, porque no hay una necesidad jurídica de hacerlo y, en segundo lugar porque es poco probable que lo haga.

Como no es obligatorio motivar las sentencias, quedará a criterio del propio TC si decide ir un poco más allá. En el evento que decida hacerlo, podríamos preguntarnos: ¿`cómo lo hará? Como ya lo señalé, el control obligatorio no tiene argumentos de inconstitucionalidad a la vista respecto de los cuales el TC se tenga que hacer cargo. Puede que ni siquiera exista una duda de constitucionalidad.

\footnotetext{
${ }^{143}$ SiLVA BASCUÑ́n (2003) p. 65.

${ }^{144}$ En la vigencia de la CPR de 1980, formalmente sólo hay cuatro leyes interpretativas y, por consiguiente, sólo hay cuatro sentencias que realizan un control de constitucionalidad obligatorio respecto de las mismas. Véase Tribunal Constitucional. Interpreta la garantía constitucional sobre derecho de propiedad en relación con reajustabilidad de pensiones. Rol No 12-1982 (1982); Tribunal Constitucional. Establece la Fecha de la Primera Elección de los Miembros de los Consejos Regionales. Rol No 158-1992 (1992); Tribunal Constitucional. Crea una planta de tropa profesional para las Fuerzas Armadas. Rol No 1192-2008 (2008), considerando No 23; Tribunal Constitucional. Ley No 17.997, Orgánica Constitucional del Tribunal Constitucional. Rol No 1288-2008 (2009), considerandos No 5 al 12. Cabe señalar que lo anterior no obsta la posible existencia de más leyes interpretativas que no hayan sido enviadas al control obligatorio.
} 
Cabe hacer presente que han existido casos en que, incluso existiendo esta duda de constitucionalidad en votos disidentes, el fallo carece de fundamentos respecto de preceptos específicos. Se trata de casos excepcionales: en efecto, de toda la muestra analizada, sólo encontré 7 sentencias donde ello ocurre. ${ }^{145} \mathrm{Si}$ el TC evita en ciertos casos referirse respecto del reproche de constitucionalidad de algún disidente, lo lógico es que lo hará con menores probabilidades si nadie plantea ninguna duda.

Así, si queremos que el TC fundamente este tipo de sentencias, entonces tendrá que asumir voluntariamente la tarea de buscar posibles razones de inconstitucionalidad, y rechazarlas de manera fundada. Esta aspiración, consustancial a la defensa del control preventivo obligatorio, es muy difícil de lograr. ¿Cómo comenzar a buscar posibles razones? Un análisis acabado implicaría un examen de todo el articulado de la CPR, tarea aparentemente poco razonable. Ello se vuelve mucho más complejo si se incorpora el análisis de los valores, principios y conceptos jurídicos indeterminados. Cada sentencia sería un tratado de Derecho Constitucional. Lo anterior resulta imposible (o muy difícil), poco razonable y, tal vez, innecesario.

Sin perjuicio de lo anterior, es posible divisar casos excepcionales en que el TC se esfuerza en la búsqueda de fundamentos constitucionales que justifican la dictación de la norma, descartando eventuales inconstitucionalidades. Del total de la muestra estudiada en este trabajo, sólo encontré 5 fallos. ${ }^{146}$ Se trata, en la

145 Véanse Tribunal Constitucional. Permite efectuar anticipos de subvenciones estatales para fines educacionales, en casos que indica. Rol No 696-2006 (2007); Tribunal Constitucional. Modifica la Ley de Copropiedad Inmobiliaria para facilitar la organización y administración de los condominios de viviendas sociales. Rol No 700-2007 (2007); Tribunal Constitucional. Modificaciones en la Ley No 17.235, sobre Impuesto Territorial, en el Decreto Ley No 3.063, de 1979, sobre Rentas Municipales, y en otros cuerpos legales. Rol No 1063-2008 (2008); Tribunal Constitucional. Ley No 17.997, Orgánica Constitucional del Tribunal Constitucional. Rol No 1288-2008 (2009); Tribunal Constitucional. Modifica el Decreto con Fuerza de Ley No 1, de 2005, del Ministerio de Economía, Fomento y Reconstrucción, referido al Tribunal de Defensa de la Libre Competencia. Rol No 1377-2009 (2009); Tribunal Constitucional. Crea el Sistema Intersectorial de Protección Social e institucionaliza el Subsistema de Protección Integral a la Infancia. Chile Crece Contigo. Rol No 1456-2009 (2009); Tribunal Constitucional. Modifica el Estatuto Orgánico de la Corporación Nacional del Cobre de Chile (CODELCO) y las normas sobre disposición de sus pertenencias mineras. Rol No 1509- 2009 (2009), donde existen disidencias no refutadas en el voto de mayoría.

${ }^{146}$ No incluyo en esta cifra los fallos que realizan declaraciones de constitucionalidad con entendidos. Véase Tribunal Constitucional. Modifica la Ley No 18.700, Orgánica Constitucional sobre Votaciones Populares y Escrutinios, con el objeto de reconocer el derecho a ser asistido en el acto de votar para las personas con discapacidad. Rol No 745- 2007 (2007); Tribunal Constitucional. Establece beneficios para el personal del Sector Salud. Rol No 805-2007 (2007); Tribunal Constitucional. Acuerdo aprobatorio relativo al Convenio No 169 sobre pueblos indígenas, adoptado por la Organización Internacional del Trabajo, de 27 de junio de 1989. Rol No 1050-2008 (2008); Tribunal Constitucional. Modificaciones en la Ley No 17.235, sobre Impuesto Territorial, en el Decreto Ley No 3.063, de 1979, sobre Rentas Municipales, y en otros cuerpos legales. Rol No 1063-2008 (2008); Tribunal Constitucional. Modifica la Leyes Nos. 19.175, Orgánica Constitucional sobre Gobierno y Administración Regional; 18.695, Orgánica Constitucional de Municipalidades, y 18.556, Orgánica Constitucional sobre Sistema de Inscripciones Electorales y Servicio Electoral. Rol No 1308-2009 (2009). 
gran mayoría de estas excepciones, de explicaciones relativas al valor jurídico constitucional del cual deriva la legitimidad de la norma sometida a control. Por supuesto, estos casos suelen dejar muchos flancos abiertos ya que, al no realizar un análisis de todo nuestro sistema constitucional (lo que es imposible o, al menos, poco factible) no eliminan necesariamente la totalidad de las dudas de constitucionalidad que puedan existir.

Las sentencias infundadas son, en los casos objeto de este trabajo, la regla general. Como una ilustración de lo anterior, resulta ilustrativo citar el primer caso de control obligatorio de constitucionalidad, manifestado en la sentencia Rol No 1, dictada el 4 de mayo de 1981. Se trató del control que realizó el TC sobre el proyecto de LOC que regula al propio TC. El control de su propia norma. Literalmente, la sentencia sólo contiene dos considerandos: el primero sostiene que el proyecto le ha sido remitido, y el segundo declara "Que el referido proyecto de ley no contiene disposición contraria a la Constitución Política de la República". ${ }^{147}$ Dicha sentencia no dice nada más, y no realiza argumentaciones relativas a justificar la constitucionalidad del mismo. El cuerpo de la sentencia tiene menos de una página.

Una vez comenzado el período democrático y ya funcionando regularmente el Congreso Nacional, el TC comenzó a incorporar a este tipo de sentencias dos considerandos adicionales: En primer lugar, se introdujo un considerando donde el TC realiza una breve referencia al tipo de materia que le es sometida, con el objeto de determinar si le corresponde o no ejercer el control. Lo normal es que en este considerando el TC defina qué materias son propias de LOC y qué materias son propias de ley simple. En segundo lugar, el TC introdujo un considerando donde constata el cumplimiento del quórum de aprobación respectivo en cada cámara legislativa, lo que implica un mínimo control constitucional de forma respecto del proyecto de ley sometido a su decisión. Como una muestra ilustrativa de lo anterior, la primera sentencia del TC producida en ejercicio del control obligatorio dictada en período democrático, de fecha 21 de noviembre de 1990 , dispone: " $8^{\circ}$.- Que consta de autos que por oficio de la Cámara de Diputados, de origen en este caso, el inciso del proyecto respectivo sometido a control de constitucionalidad ha sido aprobado en ambas Cámaras y en todos sus trámites con el quórum requerido por la Constitución Política”. ${ }^{148}$

${ }^{147}$ Tribunal Constitucional. Ley orgánica constitucional que regula la organización y funcionamiento del Tribunal Constitucional. Rol No 1 (1981).

${ }_{148}$ Tribunal Constitucional. Modifica la Ley $N^{\circ}$ 18.696, que Establece Normas Relativas al Transporte de Pasajeros. Rol No 114-1990 (1990). 
Cabe destacar que considerandos similares son incluidos en todas las sentencias que fueron objeto de estudio para la confección de este trabajo. Por ello, puede afirmarse que el control preventivo obligatorio implica, entre otras cosas, un control de quórum. Sin embargo, recordemos, este control es parcialmente falso e innecesario, por las razones que expliqué más arriba.

La naturaleza de la función de control preventivo obligatorio y la falta de argumentaciones a la vista hacen que el TC tenga pocas herramientas para realizar este examen. Por otra parte, el control preventivo implica analizar una norma que no está vigente, respecto de cuya aplicación sabemos muy poco. Como ya lo señalé citando a Shapiro, normalmente las normas legales modernas son disposiciones de un carácter frecuentemente muy general, con variadas remisiones al regulador administrativo. ${ }^{149} \mathrm{Si}$ se considera lo anterior, es bastante poco lo que podrá imaginar el TC en cuanto eventuales dudas de constitucionalidad. Y si el TC no tiene dudas de constitucionalidad, entonces difícilmente podrá fundamentar mayormente su declaración de conformidad constitucional.

Lo anterior se traduce en que el texto contenido en las sentencias emanadas del control preventivo obligatorio tiene poca probabilidad de constituir un aporte a la dogmática constitucional.

\section{ESTUDIO DE LA FUNDAMENTACIÓN DE LAS}

SENTENCIAS EMANADAS DEL CONTROL PREVENTIVO OBLIGATORIO

Para este apartado, tomé una muestra de fallos que comprende exclusivamente las sentencias emanadas del control preventivo obligatorio. En su mayoría, se refiere a casos de control de LOC. Ello, por cuanto se han dictado muy pocas sentencias que controlan la dictación de leyes interpretativas de la CPR.

La muestra comprende las sentencias dictadas en los años 2006, 2007, 2008 y 2009 (hasta el 11 de noviembre de 2009), que dan un total de $73 . .^{150}$

\footnotetext{
${ }^{149}$ SHAPIro (1993) pp. 475-479.

${ }^{150}$ Hago la precisión de que la fecha se tomó en consideración a la dictación de la sentencia y no al ingreso de la causa. Por esta razón, las memorias del TC encuentran diferencias con la muestra que realicé, sin perjuicio de que todas las sentencias analizadas provienen de la página web del mismo TC. Lo completo de este análisis se encuentra, desde luego, condicionado a que todas las sentencias del período indicado estén efectivamente en la página web. Se hace presente que hay ciertas diferencias con los números que muestra la página web. Se excluyeron ciertas sentencias de la muestra que, en la página web del TC, aparecen de la búsqueda del control preventivo obligatorio. Ello se debe, en general, a que hay algunos errores en la página web (como ocurre con las sentencias roles $642,804,1217,1293,1345)$ y a que hay causas en que el TC determinó que los preceptos controlados no son LOC, por lo que no ejerció su atribución (como ocurrió con las sentencias roles $780,813,945,1025,1150,1459,1483$ y 1491$)$.
} 
El estudio clasificó las sentencias en distintos grupos: las que aportan a la dogmática, las que no aportan y las que no pueden aportar.

\section{CUAdRo No 1}

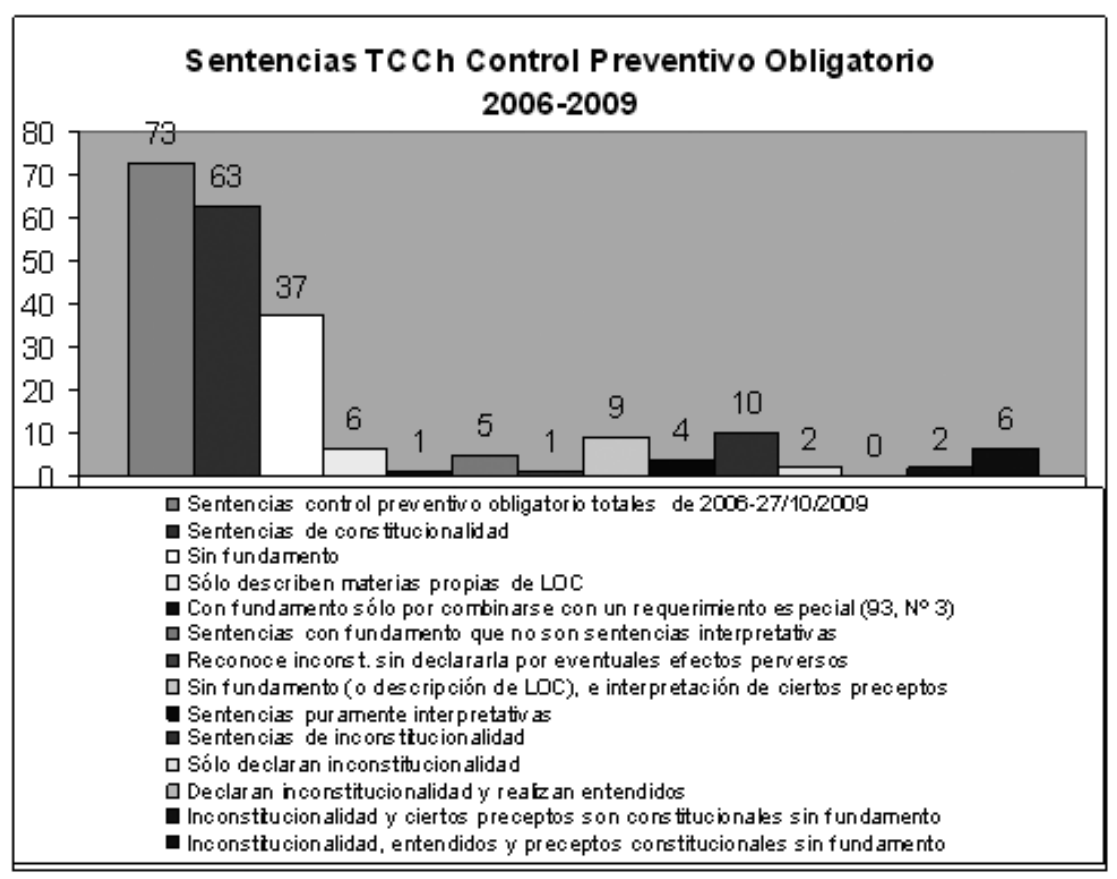

Fuente: elaboración propia utilizando datos de www.tribunalconstitucional.cl.

1. Las que aportan a la dogmática. Dentro de éstas, podemos constatar la existencia de varios subgrupos:

1.1. Aquellas que, declarando la constitucionalidad del precepto legal sometido a su decisión, tienen un fundamento claro, donde el TC hace un esfuerzo por encontrar argumentos que justifiquen la dictación de la ley. En estos casos, normalmente el TC citará alguna norma o principio constitucional que fundamenta la dictación del precepto legal. Por ejemplo, fundado en los principios del debido proceso, dirá que la autorización judicial de una medida determinada, es constitucional. Por supuesto, este tipo de sentencias son bastante escasas, probablemente por las razones que he esbozado en esta sección. Son sólo 5 casos en toda la muestra. ${ }^{151}$

${ }^{151}$ Son los roles 745, 805, 1050, 1063, 1308. 
1.2. Otro tipo de estas sentencias la representan aquellos fallos que reconocen la existencia de un vicio de constitucionalidad en el precepto, pero elude declararlo argumentando que, de declararse, las consecuencias negativas serían peores que las ventajas constitucionales de la declaración de inconstitucionalidad. Estos son casos raros y de dudosa legitimidad, que no obstante representan un aporte por cuanto el lector puede tener certeza acerca de la existencia de una duda de constitucionalidad. Sólo encontré un caso. ${ }^{152}$

1.3. También constituyen un aporte a la dogmática aquellas sentencias que, eludiendo la declaración de inconstitucionalidad, contienen algún entendido interpretativo. Este grupo es relativamente frecuente en la jurisprudencia del TC (en la muestra, encontré 13 sentencias). El aporte de estas mismas es relativo, por cuanto no siempre gozan de fundamento suficiente, razón por la cual dividí estas sentencias en dos subgrupos: por una parte están aquellas sentencias puramente interpretativas, que sólo hacen un alcance (o alcances) al precepto legal sometido al control. Sin perjuicio de las críticas que puede recibir esta técnica, este tipo de sentencias representan un aporte a la dogmática. Son 4 casos en toda la muestra. ${ }^{153}$ Por otra parte, están aquellas sentencias que interpretan ciertos preceptos legales de manera combinada con otros preceptos en que se omite mayor desarrollo. Estas últimas, en la parte que no fundamentan, podrían ser parcialmente incorporadas al grupo de fallos que las sentencias que no constituyen un aporte. En total, hay 9 casos en toda la muestra ${ }^{154}$.

2. Las que no aportan a la dogmática. Se subdividen a su vez en:

2.1. Aquellas que simplemente no tienen fundamento. Son las más frecuentes en toda la muestra, siendo la categoría más numerosa. De hecho, son 37 en toda la muestra. ${ }^{155}$

2.2. Aquellas que sólo tienen un mínimo de fundamento para esclarecer las materias propias de LOC que se someten a control. Entre las que no se remiten a precedentes anteriores y muestran un fundamento original, sólo encontré 6 en toda la muestra. ${ }^{156}$ Este fundamento sólo es útil para delimitar la extensión de las atribuciones del TC, lo que pierde sustento si se elimina la atribución del mismo.

\footnotetext{
${ }^{152}$ Es el rol 1024.

${ }^{153}$ Son los roles 762, 799, 1028, 1509.

${ }^{154}$ Son los roles 548, 663, 700, 720, 1007, 1001, 1032, 1151, 1209.

${ }^{155}$ Son los roles 475, 553, 633, 687, 696, 801, 830, 948, 992, 1000, 999, 1016, 1023, 1022, 1027, 1047, $1054,1035,1224,1208,1237,1274,1270,1315,1355,1387,1403,1377,1417,1415,1428,1439$, 1440, 1446, 1472, 1489, 1503.

${ }^{156}$ Son los roles 466, 474, 1031, 1059, 1192, 1508.
} 
Por esta razón, las incluí dentro de las sentencias que no constituyen un aporte a la dogmática. ${ }^{157}$

2.3. Aquellas que se combinan con requerimientos de control eventual. En este último caso, si se encuentra algún tipo de fundamento, ello se debe a la existencia de una duda de constitucionalidad manifestada por los requirentes que provocaron el control eventual. Por consiguiente, si existe aporte, éste se deberá a que hubo coexistencia con esta otra atribución, pero no a un aporte del control obligatorio. En todo caso, esto es muy raro que se produzca (en la muestra analizada, sólo encontré un caso ${ }^{158}$ ).

No obstante todo lo anterior, a este grupo podrían sumarse otras 6 sentencias del primer grupo: aquellas que contienen ciertos entendidos aislados que acompañan declaraciones de inconstitucionalidad.

3. Aquellas que declaran una inconstitucionalidad. El aporte de estas sentencias es evidente, ya que contribuyen a fijar el sentido del derecho e influyen en la configuración del sistema normativo. Sin embargo, las trato en un grupo especial, debido a la existencia de la obligación jurídica de fundamentar las mismas, lo que las vuelve excepcionales dentro del control preventivo obligatorio (o, mejor dicho, las hace volver a la regla general). La frecuencia de estas sentencias no es tan escasa, pero igualmente es baja. Son 10 en toda la muestra. Sin embargo, hay que hacer algunos matices, ya que éstas deben subclasificarse:

3.1. Aquellas que simplemente declaran una inconstitucionalidad. Éstas son las que verdaderamente aportan sin matiz alguno. Son sólo 2 en toda la muestra. ${ }^{159}$

3.2. Aquellas que declaran la inconstitucionalidad de ciertos preceptos, pero otros son declarados constitucionales sin mayor fundamento. Parcialmente, estas sentencias no constituyen un aporte. Son 2 casos. ${ }^{160}$

3.3. Aquellas que declaran la inconstitucionalidad, contienen entendidos interpretativos y ciertos preceptos son declarados constitucionales sin mayor fundamento. Al igual que las sentencias del grupo anterior, estos fallos no constituyen, parcialmente, un aporte. Son 6 casos. ${ }^{161}$

Estos últimos dos subgrupos de sentencias (que sumados constituyen 8 fallos) deberían estar parcialmente en la categoría de fallos que no constituyen un aporte.

\footnotetext{
${ }^{157}$ No representan un aporte más allá de la discusión relativa a las LOC. No obstante, ello es significativo para efectos de determinar el quórum.

${ }^{158}$ Rol 560.

${ }^{159}$ Son los roles 1170 y 1316.

${ }^{160}$ Son los roles 536, 1017.

${ }^{161}$ Son los roles 521, 719, 1051, 1243, 1363, 1288.
} 
Considerando todas las categorías elaboradas anteriormente, y sin considerar los casos de aporte meramente parcial, se puede inferir que un $60 \%$ de las sentencias emanadas del control preventivo obligatorio no constituye un aporte a la dogmática, sin perjuicio de que, dentro de los otros grupos, también encontramos sentencias que, parcialmente, podrían incorporarse a esta categoría, lo que haría subir esta cifra de manera sustancial.

Evidentemente que se trata de un número de sentencias alto, como puede apreciarse en los cuadros.

\section{Cuadro No 2}

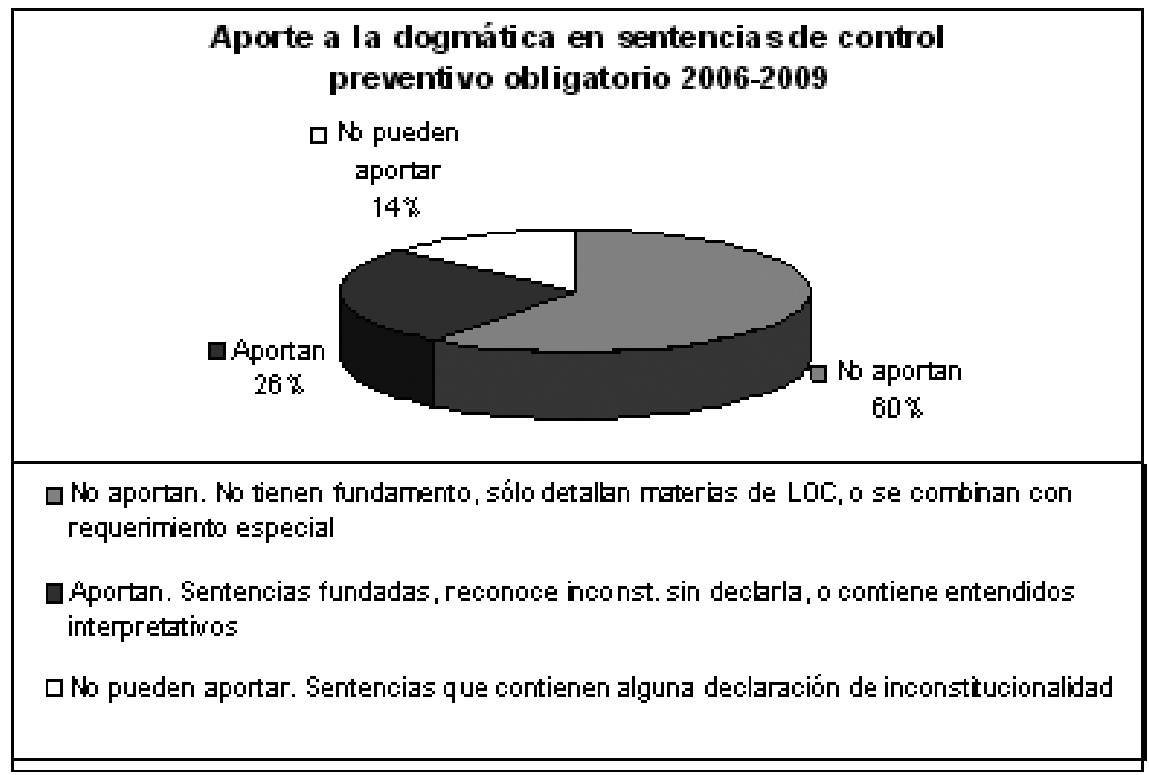

Fuente: elaboración propia utilizando datos de www.tribunalconstitucional.c.

Todo lo anterior constituye un elemento relevante para agregar a la discusión relativa a la conveniencia o inconveniencia de mantener el control preventivo obligatorio. Si se considera que la dogmática jurisprudencial es importante y necesaria para generar bienes jurídicos como certeza e igualdad en la aplicación de la ley, entonces no puede obviarse este elemento. Un $60 \%$ de sentencias que no constituyen aporte en absoluto es una cifra muy significativa, aunque, reconozco, no concluyente.

La ausencia de motivación de las sentencias es consecuencia de las desventajas del control preventivo, en especial de la última, que ya expliqué en la sección I de este trabajo. El TC tiene pocas herramientas para enfrentar el análisis que se le pide. 


\section{CONCLUSIONES}

1. Hay poca literatura nacional relativa a la conveniencia o inconveniencia de mantener el control preventivo obligatorio. Sin perjuicio de ello, hay suficiente material como para desarrollar este debate con cierta profundidad. En este debate, la carga de la prueba pertenece a quien intenta demostrar la conveniencia del mismo, debido a su carácter excepcional.

2. La naturaleza jurídica (y no jurisdiccional) del control preventivo obligatorio es un punto muy relevante en el debate, ya que permite sostener ciertos argumentos favorables o desfavorables respecto al mismo.

3. Existen muchas razones para justificar la existencia del control obligatorio. Sin embargo, todas ellas son susceptibles de rechazo o, a lo menos, de argumentos que disminuyen su importancia. Por otra parte, existen varias razones que demuestran la desventaja del control obligatorio. Algunas de ellas no tienen mayor procedencia o son susceptibles de ser matizadas en ciertos aspectos. Sin perjuicio de ello, hay otras desventajas que persisten y que se pueden observar de manera palpable. El ejercicio práctico del control preventivo demuestra el efecto que estas desventajas produce en la jurisprudencia, siendo la ausencia de motivación un factor muy relevante a considerar. El sello de constitucionalidad introducido por la modificación a la LOC del TC agrava las cosas, como se demostró.

4. La dogmática jurídica en las sentencias del TC es un elemento muy importante a analizar, ya que representa la utilidad de los fallos más allá de las causas que resuelven. Con ellas el TC envía señales relativas a su concepción del Derecho como sistema y a los criterios que está usando. Ello tiene enormes beneficios en materia de seguridad jurídica e igualdad en la aplicación de la ley.

5. La dogmática se puede medir en razón del nivel de fundamentación que experimentan las sentencias. De acuerdo al estudio realizado en la sección II acerca de la motivación de los fallos, se demuestra que la dogmática es escasa en el control preventivo obligatorio, razón por la cual podemos cuestionar su utilidad. Este argumento se suma a la lista de desventajas desarrolladas en la sección I.

\section{BiBLIOGRAFÍA CITADA}

Aldunate Lizana, Eduardo (2008): Derechos Fundamentales (Santiago, LegalPublishing).

Aldunate Lizana, Eduardo (2005): "Problemas del Control Preventivo de Constitucionalidad de las Leyes", en Revista de Estudios Constitucionales, (Año No 3, No 1), pp. 119-126. 
Alegre Martínez, Miguel Ángel (2007): "El resurgimiento del debate sobre el control previo de constitucionalidad en España: experiencia y perspectivas", en Revista Iberoamericana de Derecho Procesal Constitucional, (No 8), pp. 3-29.

Andrade Geywitz, Carlos (1971): Elementos de Derecho Constitucional Chileno, $2^{\text {a }}$ edición (Santiago, Editorial Jurídica de Chile)

Arancibia Mattar, Jaime, Brahm García, Enrique y Irarrázabal Gomien, Andrés (2008a): Actas del Consejo de Estado en Chile (1976-1990) (Santiago, Ediciones Centro de Estudios Bicentenario) Tomo I.

Arancibia Mattar, Jaime, Brahm García, Enrique y Irarrázabal Gomien, Andrés (2008b): Actas del Consejo de Estado en Chile (1976-1990) (Santiago, Ediciones Centro de Estudios Bicentenario) Tomo II.

ATRIA, Fernando (2000): Revisión Judicial: El Síndrome de la Victima Insatisfecha, [fecha de consulta: 21 de diciembre de 2009. Disponible en: http://www. cepchile.cl/dms/lang $1 / \mathrm{doc} 1081 . h \mathrm{tml}$

Atria, Fernando (1993) "Tribunal Constitucional y Objeción Democrática", en Revista Chilena de Derecho, Vol. 20 (Nos. 2-3), pp. 367-378.

Beardsley, James E. (1972) "The Constitutional Council and Constitutional Liberties in France", en American Journal of Comparative Law, Vol. 20 (№ 3), pp. 431-452.

Bon, Pierre (1993): "El Conseil Constitutionnel francés y el modelo de Cortes Constitucionales europeas", en Revista Chilena de Derecho, Vol. 20 ( $\mathrm{No}^{\circ} .2-3$ ), pp. 379-394.

Bordalí Salamanca, Andrés (2005): "Análisis crítico del control preventivo y represivo de constitucionalidad de las normas jurídicas por los Tribunales Constitucionales", en NogueIra Alcalá, Humberto, Jurisdicción Constitucional en Chile y América Latina: presente y prospectiva (Santiago, LexisNexis), pp. 213-254.

BuchHeister Rosas, Axel y Soto Velasco, Sebastián (2005): “Criterios para la calificación de normas orgánico constitucionales en la jurisprudencia del Tribunal Constitucional", en Revista Chilena de Derecho, Vol. 32 (N²), pp. 253-275.

Bulnes Aldunate, Luz (1984): "La Ley Orgánica Constitucional”, en Revista Chilena de Derecho, Vol. 11 (Nos. 2-3), pp. 227-239.

Caldera Delgado, Hugo (1984): "Ley Orgánica Constitucional y Potestad Reglamentaria", en Revista Chilena de Derecho, Vol. 11 (Nos. 2-3), pp. 456-459.

Comisión Estudios de la Nueva Constitución (1973-1978): Actas Oficiales de la Comisión Constituyente, [fecha de consulta: 21 de diciembre de 2009]. Disponible en: http://www.bcn.cl/lc/cpolitica/actas oficiales-r 
De la Cruz Millar, Alicia (2007): Decisiones con Reserva de Interpretación y el Tribunal Constitucional Chileno: 20 años evitando la inconstitucionalidad (Santiago, Tesis para optar al grado de Magíster en Derecho Público, Pontificia Universidad Católica de Chile).

Evans de la Cuadra, Enrique (1970): Relación de la Constitución Politica de la República de Chile (Santiago, Editorial Jurídica de Chile).

FAVOREU, Louis (1994): Los tribunales constitucionales (Barcelona, Editorial Ariel).

Favoreu, Louis (2001): "La Constitucionalización del Derecho", en Revista de Derecho (Valdivia), Vol. XII, pp. 31-43.

Fermandois Vohringer, Arturo (2005): "Efecto vinculante de las sentencias del Tribunal Constitucional: ¿̇mito o realidad?”, en ZúNiga Urbina, Francisco Reforma Constitucional (Santiago, LexisNexis) pp. 685-696.

FernÁndez GonzÁlez, Miguel Ángel (1997): "Sentido y alcance del artículo 83, inciso $3^{\circ}$ de la Constitución”, en Gaceta Jurídica, (No 210), pp. 13-22.

Fernández GonZÁlez, Miguel Ángel (2003): "Visión prospectiva en relación con la regulación constitucional de los tratados internacionales", en Revista Ius et Praxis, (Año 9, No 1), pp. 485-511.

Friedrich, Carl J. (1959) "The New French Constitution in Political and Historical Perspective”, en Harvard Law Review, Vol. 72 (No 5), pp. 801-837.

GarCía, José Francisco (2003): "El control de constitucionalidad en el Federalista y los fundamentos de una sociedad libre", en Revista Chilena de Derecho, Vol. 30 (No 3), pp. 491-514.

Gomes Canotilho, José Joaquín (2000): Direito Constitucional e Teoria da Constituicao (7a edición, Coimbra, Portugal, Livraria Almedina).

Henríquez Viñas, Miriam (2009): Las Fuentes Formales del Derecho (Santiago, LegalPublishing).

Henríquez Viñas, Miriam (2007): "Improcedencia del control represivo de constitucionalidad de tratados internacionales", en Revista Estudios Constitucionales, (Año 5, No 1), pp. 119-126.

Hübner Gallo, Jorge (1984): Introducción al Derecho, 5a edición (Santiago, Editorial Jurídica de Chile).

KeLSEN, Hans (2002) ¿Quién debe ser el defensor de la Constitución?, reimpresión de la 2a edición (Madrid, Tecnos).

Kramer, Larry D. (2001): "Foreword: We the Court", en Harvard Law Review, Vol. 115 (No 1), pp. 4-169. 
Mesquita Ceia, Eleonora (2007): "La inaplicabilidad de la doctrina de las cuestiones políticas en el cambio de las relaciones exteriores: ¿Deben los tratados internacionales ser considerados actos no justiciables?, en Revista Estudios Constitucionales, (Año 5, No 1), pp. 289-310.

Meyson-Renoux, Catherine (1993): "El debate en Francia sobre el proyecto presidencial de reforma constitucional (26 de junio de 1993)", en Revista Chilena de Derecho, Vol. 20 ( $\mathrm{No}^{\circ}$ s. 2-3), pp. 583-593.

Ministerio Secretaría General de la Presidencia. División Jurídico-Legislativa (2000): Doctrina Constitucional del Presidente Eduardo Frei Ruiz-Tagle (Santiago, Impreso en Talleres LOM Ediciones) Tomo II.

Moderne, Franck (1993): "El control previo de constitucionalidad en la Europa contemporánea”, en Revista Chilena de Derecho, Vol. 20 (Nos. 2-3), pp. 409-416.

Morton, F. L. (1988): "Judicial Review in France: A Comparative Analysis", en American Journal of Comparative Law, Vol. 36 (No 1), pp. 89-110.

MuÑoz LeÓN, Fernando (2006): "Leyes orgánico-constitucionales: insatisfactoria rigidización de la democracia", en Anuario de Derecho Constitucional Iberoamericano (Konrad Adenauer Stiftung), pp. 115-129.

Nogueira AlcalÁ, Humberto (2007): "Reforma constitucional de 2005 y control de constitucionalidad de tratados internacionales", en Revista Estudios Constitucionales, (Año 5, No 1), pp. 59-88.

Pfeffer Urquiaga, Emilio (1998): "Algunos problemas que se derivan del Control Obligatorio de Constitucionalidad que ejerce el Tribunal Constitucional sobre las Leyes Orgánicas Constitucionales", en Revista Ius Et Praxis (Año 4, № 1), pp. 259-268.

Pfeffer Urquiaga, Emilio (2005): Reformas Constitucionales 2005 (Santiago, Editorial Jurídica de Chile).

PeÑA Torres, Marisol (2006): "El precedente constitucional emanado del Tribunal Constitucional y su impacto en la función legislativa”, en Revista Estudios Constitucionales, (Año 4, No 1), pp. 173-184.

Posner, Richard A. (2007): El análisis económico del derecho, 2a edición (Traducc. Eduardo L. SuÁrez, México D.F., Fondo de Cultura Económica).

Renoux, Thierry S. (1993): "El Consejo Constitucional y el Poder Judicial en Francia y en el modelo europeo de control de constitucionalidad de las leyes", en Revista Chilena de Derecho, Vol. 20 ( $\mathrm{No}_{\text {s. }}$ 2-3), pp. 442-447.

Ribera Neumann, Teodoro (2007): "Los tratados internacionales y su control a posteriori por el Tribunal Constitucional”, en Revista Estudios Constitucionales, (Año 5, No 1), pp. 89-118. 
Ríos Álvarez, Lautaro (1983): “Las Leyes Orgánicas Constitucionales”, en Revista Chilena de Derecho, Vol. 10 (No 1), pp. 39-44.

Rousseau, Dominique (2002): La justicia Constitucional en Europa (Madrid, Centro de Estudios Políticos y Constitucionales).

SHAPIRO, Martin (1993): "Revisión judicial a priori y a posteriori: los modelos norteamericano y europeo", en Revista Chilena de Derecho, Vol. 20 (Nos. 2-3), pp. 475-479.

Silva Bascuñán, Alejandro (1984): "Interpretación de la Carta a través del Legislador", en Revista Chilena de Derecho, Vol. 11 ( $\mathrm{No}_{\text {s. }}$ 2-3), pp. 351-363.

Silva Bascuñán, Alejandro (2003): Tratado de Derecho Constitucional, 2a edición (Santiago, Editorial Jurídica de Chile), Tomo IX.

Silva Bascuñán, Alejandro y Silva Gallinato, María Pía (1988): "Efectos de la Resolución de Constitucionalidad" en Revista Chilena de Derecho, Vol. 15, pp. 311-340.

Silva Cimma, Enrique (2008): El Tribunal Constitucional de Chile (1971-1973), $2^{a}$ edición (Santiago, Cuadernos del Tribunal Constitucional).

Squella Narducci, Agustín (2004): Introducción al Derecho (Santiago, Editorial Jurídica de Chile).

Soто Kloss, Eduardo (2009): Derecho Administrativo. Temas Fundamentales (Santiago, LegalPublishing).

Tallon, Denis (1979): “The Constitution and the Courts in France”, en American Journal of Comparative Law, Vol. 27 (No 4), pp. 567-576.

Tribunal Constitucional (2006): Memoria del Tribunal Constitucional 2005 (Santiago).

Tribunal Constitucional (2007): Memoria del Tribunal Constitucional 2006 (Santiago).

Tribunal Constitucional (2009): Memoria del Tribunal Constitucional 20072008 (Santiago).

Vargas, Juan Enrique, Peña, Carlos y Correa, Jorge (2001): El Rol del Estado y el Mercado en la Justicia (Santiago, Universidad Diego Portales)

Verdugo Ramírez, Sergio (2008): "La Declaración de Inconstitucionalidad de las leyes como control represivo abstracto. Una especie de nulidad de Derecho Público atenuada en sus efectos", en Revista Actualidad Jurídica (Año IX, No 18), pp. 247-297.

Verdugo Ramírez, Sergio (2009a): "Regla de Mayoría y Democracia”, en Revista Actualidad Jurídica (Año X, No 20) Tomo II, pp. 597-633. 
Verdugo Ramírez, Sergio (2009b): “Estatuto Fundamental de las Leyes Orgánicas Constitucionales”, en prensa.

Verdugo Ramírez, Sergio (2009c): "El sello de constitucionalidad de los preceptos legales declarados constitucionales en el control preventivo", en Revista de Derecho y Ciencias Penales, No 13 (Universidad San Sebastián), pp. 57-81.

VieHWeg, Theodor (1991): Tópica y Filosofía de Derecho (Barcelona, Editorial Gedisa).

Williams BenaVente, Jaime (1999): Lecciones de Introducción al Derecho, 3a edición (Santiago, Ediciones Fundación de Ciencias Humanas).

Zapata Larraín, Patricio (2008) Justicia Constitucional (Santiago, Editorial Jurídica de Chile).

Zapata Larraín, Patricio (1994): La Jurisprudencia del Tribunal Constitucional (Santiago, Corporación Tiempo 2000).

Zapata LaRraín, Patricio (1993) "El precedente en la jurisprudencia constitucio-

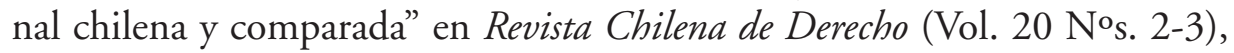
pp. 499-508.

ZúNiga Urbina, Francisco (2006) "Sentencias del Tribunal Constitucional y el Poder Judicial: el valor del precedente”, en Revista Estudios Constitucionales, (Año 4, No 1), pp. 151-172.

\section{SENTENCIAS CITADAS}

Tribunal Constitucional. Rol No 1. 4 mayo 1981. [Fecha de consulta: 21 de diciembre de 2009]. Disponible en: http://www.tribunalconstitucional.cl/ index.php/sentencias/view/607

Tribunal Constitucional. Rol No 12-1982. 16 julio 1982. [Fecha de consulta: 21 de diciembre de 2009]. Disponible en: http://www.tribunalconstitucional.cl/ index.php/sentencias/view/597

Tribunal Constitucional. Rol No 33-1985. 24 septiembre 1985. [Fecha de consulta: 23 de diciembre de 2009]. Disponible en: http://www.tribunalconstitucional. cl/index.php/sentencias/view/576

Tribunal Constitucional. Rol No 114-1990. 21 noviembre 1990. [Fecha de consulta: 21 de diciembre de 2009]. Disponible en: http://www.tribunalconstitucional.cl/index.php/sentencias/view/498

Tribunal Constitucional. Rol No 158-1992. 22 octubre 1992. [Fecha de consulta: 21 de diciembre de 2009]. Disponible en: http://www.tribunalconstitucional. cl/index.php/sentencias/view/455 
Tribunal Constitucional. Rol No 309-2000. 4 de agosto de 2000. [Fecha de consulta: 21 de diciembre de 2009]. Disponible en: http://www.tribunalconstitucional.cl/index.php/sentencias/view/310

Tribunal Constitucional. Rol No 466-2006. 2 enero 2007. [Fecha de consulta: 21 de diciembre de 2009]. Disponible en: http://www.tribunalconstitucional.cl/ index.php/sentencias/view/158

Tribunal Constitucional. Rol No 681-2006. 26 marzo 2007. [Fecha de consulta: 21 de diciembre]. Disponible en: http://www.tribunalconstitucional.cl/index. $\mathrm{php} /$ sentencias/view/69

Tribunal Constitucional. Rol No 696-2006. 2 enero 2007. [Fecha de consulta: 21 de diciembre de 2009]. Disponible en: http://www.tribunalconstitucional.cl/ index.php/sentencias/view/61

Tribunal Constitucional. Rol No 700-2007. 18 enero 2007. [Fecha de consulta: 21 de diciembre de 2009]. Disponible en: http://www.tribunalconstitucional. cl/index.php/sentencias/view/58

Tribunal Constitucional. Rol No 745-2007. 29 marzo 2007. [Fecha de consulta: 21 de diciembre de 2009]. Disponible en: http://www.tribunalconstitucional. cl/index.php/sentencias/view/31

Tribunal Constitucional. Rol No 805-2007. 24 julio 2007. [Fecha de consulta: 21 de diciembre de 2009]. Disponible en: http://www.tribunalconstitucional. cl/index.php/sentencias/view/13

Tribunal Constitucional. Rol No 1050-2008. 3 abril 2008. [Fecha de consulta: 21 de diciembre de 2009]. Disponible en: http://www.tribunalconstitucional. cl/index.php/sentencias/view/904

Tribunal Constitucional. Rol No 1063-2008. 12 junio 2008. [Fecha de consulta: 21 de diciembre de 2009]. Disponible en: http://www.tribunalconstitucional. cl/index.php/sentencias/view/960

Tribunal Constitucional. Rol No 1192-2008. 21 octubre 2008. [Fecha de consulta: 21 de diciembre de 2009]. Disponible en: http://www.tribunalconstitucional. cl/index.php/sentencias/view/1030

Tribunal Constitucional. Rol No 1308-2009. 27 enero 2009. [Fecha de consulta: 21 de diciembre de 2009]. Disponible en: http://www.tribunalconstitucional. cl/index.php/sentencias/view/1093

Tribunal Constitucional. Rol No 1377-2009. 23 junio 2009. [Fecha de consulta: 21 de diciembre de 2009]. Disponible en: http://www.tribunalconstitucional. cl/index.php/sentencias/view/1176 
Tribunal Constitucional. Rol No 1440-2009. 30 julio 2009. [Fecha de consulta: 21 de diciembre de 2009]. Disponible en: http://www.tribunalconstitucional. cl/index.php/sentencias/view/1198

Tribunal Constitucional. Rol No 1288-2008. 25 agosto 2009. [Fecha de consulta: 21 de diciembre de 2009]. Disponible en: http://www.tribunalconstitucional. cl/index.php/sentencias/view/1214

Tribunal Constitucional. Rol No 1456-2009. 25 agosto 2009. [Fecha de consulta: 21 de diciembre de 2009]. Disponible en: http://www.tribunalconstitucional. cl/index.php/sentencias/view/1213

Tribunal Constitucional. Rol No 1287-2008. 8 de septiembre de 2009. [Fecha de consulta: 21 de diciembre de 2009]. Disponible en http://www.tribunalconstitucional.cl/index.php/sentencias/view/1219

Tribunal Constitucional. Rol No 1489-2009. 22 septiembre 2009. [Fecha de consulta: 21 de diciembre de 2009]. Disponible en: http://www.tribunalconstitucional.cl/index.php/sentencias/view/1226

Tribunal Constitucional. Rol No 1503-2009. 8 octubre 2009. [Fecha de consulta: 21 de diciembre de 2009]. Disponible en: http://www.tribunalconstitucional. cl/index.php/sentencias/view/1238

Tribunal Constitucional. Rol No 1509-2009. 27 octubre 2009. [Fecha de consulta: 21 de diciembre de 2009]. Disponible en: http://www.tribunalconstitucional. cl/index.php/sentencias/view/1241

Tribunal Constitucional. Rol No 1382-2009. 27 octubre 2009). [Fecha de consulta: 21 de diciembre de 2009]. Disponible en: http://www.tribunalconstitucional.cl/index.php/sentencias/view/1246

Tribunal Constitucional. Rol No 1504-2009. 3 noviembre 2009. [Fecha de consulta: 21 de diciembre de 2009]. Disponible en: http://www.tribunalconstitucional.cl/index.php/sentencias/view/1250

Tribunal Constitucional. Rol No 1246-2008. 1 diciembre 2009. [Fecha de consulta: 21 de diciembre de 2009]. Disponible en: http://www.tribunalconstitucional.cl/index.php/sentencias/view/1264 